ABSTRACT

Title of Dissertation / Thesis: $\quad$ RECRUITMENT RESPONSES OF BENTHIC INFAUNA TO MANIPULATED SEDIMENT GEOCHEMICAL PROPERTIES IN NATURAL FLOWS

Steven John Engstrom, Master of Science, 2004

Dissertation / Thesis Directed By:

Assistant Professor Roberta L. Marinelli, Marine, Estuarine, and Environmental Science Program

Recent studies have shown that local variation in sediment geochemistry can have significant effects on settlement rates of benthic invertebrates. For example, elevated porewater ammonium concentrations in soft-sediment benthic systems may result in decreased recruitment rates of settling larvae. Recruitment responses of the benthic polychaete Arenicola cristata and the bivalve Mercenaria mercenaria to varying ammonium concentrations were measured in realistic flow environments. Experiments made novel use of ammonium-spiked polyacrylamide gels placed beneath field-collected sediment, which produced predictable porewater ammonium concentrations. Post-larval arenicolids and Mercenaria were allowed to settle in an annular flume containing sediment treatments with varying ammonium concentrations. Porewater ammonium data indicated successful manipulation of geochemical properties without contamination of overlying water. In Mercenaria trials, recruit retention was low. For Arenicola trials, significant retention differences 
were observed as a function of ammonium concentration, and indicate that ammonium plays a significant role in determining recruitment patterns and hence juvenile abundance. 


\title{
RECRUITMENT RESPONSES OF BENTHIC INFAUNA TO MANIPULATED SEDIMENT GEOCHEMICAL PROPERTIES IN NATURAL FLOWS
}

\author{
By \\ Steven John Engstrom \\ Thesis submitted to the Faculty of the Graduate School of the \\ University of Maryland, College Park, in partial fulfillment \\ of the requirements for the degree of \\ Master of Science \\ 2004
}

Advisory Committee:

Assistant Professor Roberta L. Marinelli, Chair Associate Professor Evamaria Koch

Professor Roger I. E. Newell 
(C) Copyright by

Steven John Engstrom

2004 


\section{ACKNOWLEGEMENTS}

I thank the Chesapeake Biological Laboratory for providing a CBL graduate fellowship and the National Science Foundation for research support (NSF OCE0049065 to Roberta Marinelli). I also thank Dr. Roberta Marinelli for her countless efforts and helpful advice, her kind and valuable guidance, and her time. I thank my committee members Dr. Roger Newell and Dr. Evamaria Koch for their assistance with my research and preparation of my thesis. I thank Mr. George Waldbusser for his advice, perspectives and friendship. I am deeply thankful for the assistance provided by Dr. Sarah Woodin, Ms. Erin Wolfe, Mr. Bud Millsaps and Dr. Dave Secor. I am indebted to Dr. Roger Newell, Dr. Elka Porter and Dr. Larry Sanford for allowing me to use the annular flume and bring it to CBL. I thank my parents, John and Alice Engstrom for their encouragement and provisions and Kate Dobe for understanding me and for her enduring kindness and support. 


\section{LIST OF FIGURES}

Figure 1. Change in overlying water $\mathrm{NH}_{4}{ }^{+}$concentration over time in a bare (no sediment) gel experiment.

Figure 2. Flux of $\mathrm{NH}_{4}^{+}$from bare (no sediment) acrylamide gels produced with ammonium persulfate (APS) and potassium persulfate (KPS).

Figure 3. Photograph of the annular flume at the Chesapeake Biological Laboratory.

Figure 4. Diagram of the section and treatment subsection setup within the annular flume.

Figure 5. Velocity profile above the sediment water interface (SWI) at ring speed 4.5 RPM.

Figure 6. Diagram of new juvenile addition, flow initiation and sampling sequence.

Figure 7. Flux of $\mathrm{NH}_{4}{ }^{+}$from bare (no sediment) acrylamide gels into overlying water.

Figure 8. Flux of $\mathrm{NH}_{4}{ }^{+}$from acrylamide gels covered with varying depths of sediment on top of gels.

Figure 9. Porewater $\mathrm{NH}_{4}{ }^{+}$concentrations for predesignated Low, Medium, and High treatments in the sandwich flume experiments.

Figure 10. Proportion of juvenile Arenicola and Mercenaria individuals remaining in Low, Medium, and High core treatments in the sandwich flume experiments.

Figure 11. Test of the effect of new juvenile addition on overlying water (OLW) and porewater (PW) ammonium concentrations for each treatment in Mercenaria annular flume experiments

Figure 12. Porewater $\mathrm{NH}_{4}{ }^{+}$concentrations for Low and High treatments for Mercenaria annular flume experiments.

Figure 13. Test of the effect of new juvenile addition on overlying water (OLW) and porewater $(\mathrm{PW}) \mathrm{NH}_{4}{ }^{+}$concentrations for Arenicola annular flume experiments.

Figure 14. Porewater $\mathrm{NH}_{4}{ }^{+}$concentrations for Control, Low and High treatments for Arenicola annular flume experiments.

Figure 15. Proportion of Arenicola cristata individuals found in Control, Low and High sediment treatments for all trials at end of experiment compared to number initially added. 


\section{TABLE OF CONTENTS}

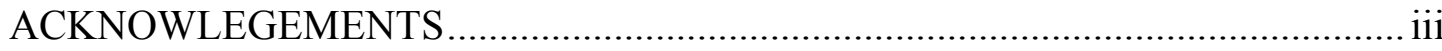

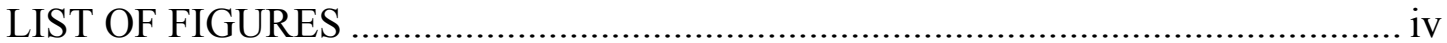

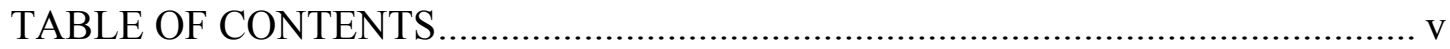

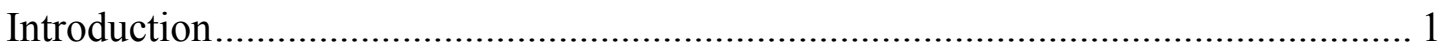

I. The Soft-Sediment Benthic Environment........................................................... 1

II. Larval Dispersal and Recruitment from an Evolutionary Perspective.................. 2

III. Recruitment and the Role of Physical, Chemical and Biological Processes ...... 4

IV. Infaunal Recruitment Processes - The Chemical Environment .......................... 6

V. Larval Recruitment Processes - Disturbance and Recruitment ........................... 8

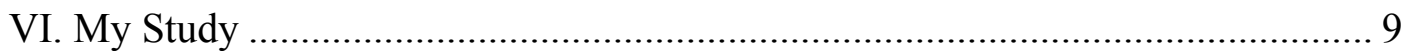

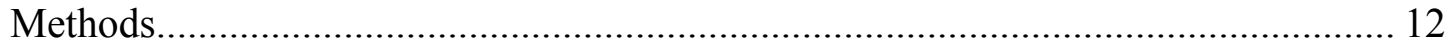

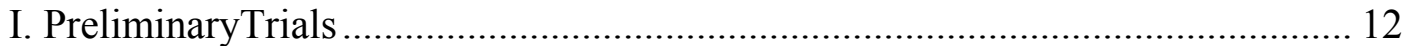

A. Diffusion Experiments.............................................................................. 12

B. Initial Tests of Mercenaria and Arenicola Responses to Ammonium - "Sandwich"

Flume Experiments..................................................................................... 18

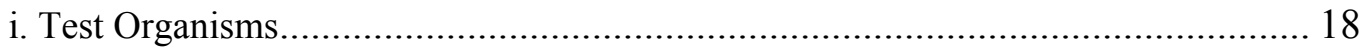

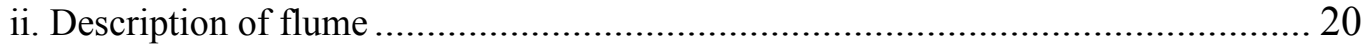

iii. Preparation of experimental cores ................................................................ 20

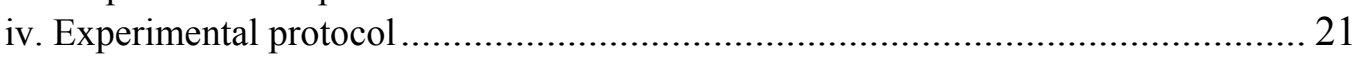

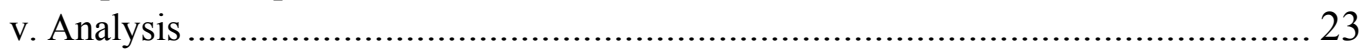

C. Hydrodynamic Characterization of Annular Flume ............................................. 24

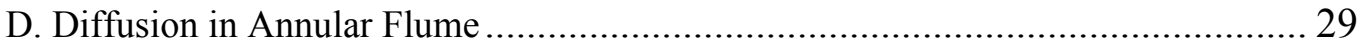

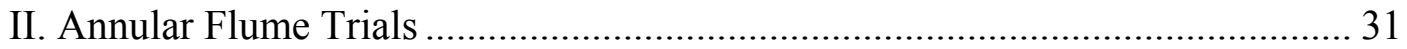

A. Mercenaria Experiments ................................................................................... 31

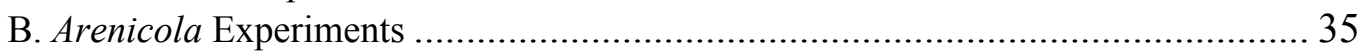

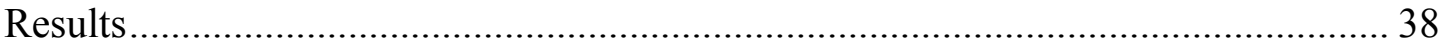

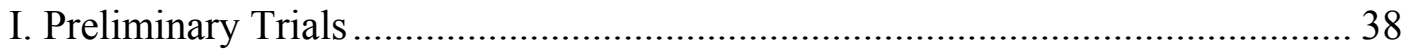

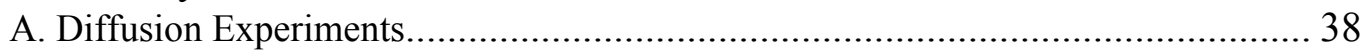

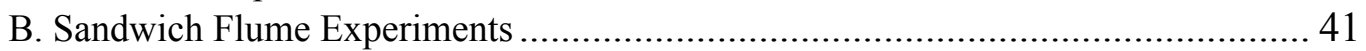

C. Preliminary Annular Flume Trials ..................................................................... 44

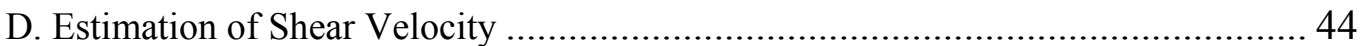

II. Annular Flume Trials ...................................................................................... 46

A. Mercenaria Experiments ................................................................................. 46

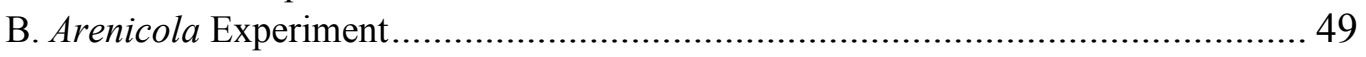

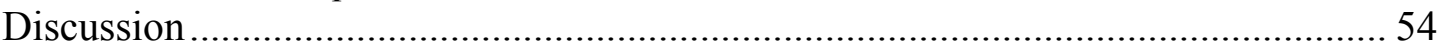

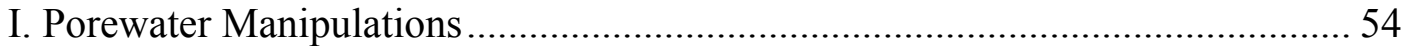

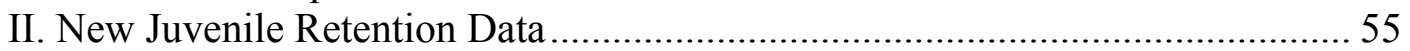

A. Mercenaria Experiments ………………………………………………..... 55

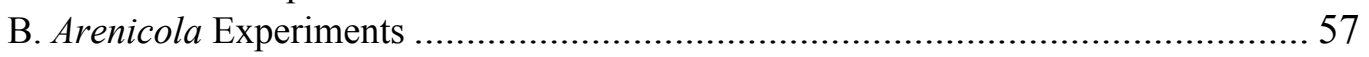

III. Methodological Considerations …………………....................................... 58

IV. Significance of Post-Settlement Choice .......................................................... 59

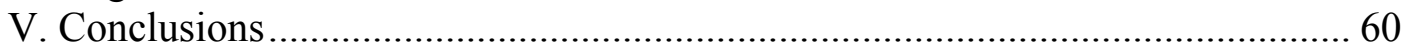

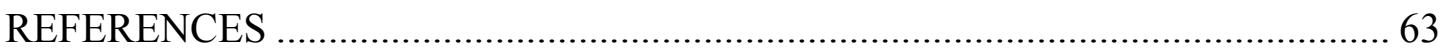




\section{Introduction}

\section{The Soft-Sediment Benthic Environment}

Soft-sediment benthic systems are physically, chemically, and biologically diverse environments that play an important role in global elemental cycling. Infaunal organisms greatly modify rates and transfers of carbon and nitrogen, particularly in nearshore systems. As such, it is important to understand the processes that structure infaunal community composition. Competition, predation, and disturbance are important and long-recognized regulators of infaunal community structure and interactions. For example, investigations of predation in benthic environments have revealed strong trophic linkages among infauna and bottom feeding fishes and with significant influences on infaunal abundance and distribution (Marcus and Boero 1998). Competitive interactions related to food and/or space can promote density-dependent migration for infaunal deposit feeders (Ambrose 1986) as well as suspension feeders (Powers and Peterson 2000), altering patterns of abundance as well as rates and pathways of biogeochemical processes (Marinelli and Williams 2003). Disturbance processes operate on a wide range of spatial and temporal scales. Their effects on mortality, and the dynamics of recolonization have long been considered significant forcing functions of community dynamics (Dayton 1971; Levin 1984; Krager and Woodin 1993).

The long-standing idea of recruitment limitation has led many to investigate how recruitment success affects community structure. Thorson (1950) suggested that 
variation found in adult communities is created by the variation in recruitment success. Although he maintained that increased time in the water column ultimately leads to decreased recruitment success and high variability in the adult population, a thorough identification and understanding of the sources of variation in recruitment success is lacking. Recruitment success depends on a combination of the species' recruitment strategy in addition to environmental characteristics such as organic content (Pearson and Rosenberg 1978), local hydrodynamics (Navarette and Weiters 2000), and the presence of adult populations (Pawlik 1988, 1990; Osman and Whitlatch 1995; Biggers and Laufer 1999). The integration of intrinsic and oftenunpredictable extrinsic factors involved in determining recruitment patterns and success provides for a complex response.

\section{Larval Dispersal and Recruitment from an Evolutionary Perspective}

Many benthic organisms lack the ability to move great distances as adults. For benthic infauna such as polychaetes and bivalves, energy costs and increased exposure to predation and disturbance events limit activities to small-scale movements during adulthood. Instead, some infaunal organisms travel considerable distances during a planktonic larval stage after release by the adult. Crisp (1974) suggested that the reason for a larval planktonic stage is to facilitate dispersal over relatively large distances. However, because many recruits end up very near to the original adult populations dispersal may serve other purposes. Trade-offs exist between organisms that employ larger scale dispersal versus local recruitment. 
Planktonic stages may break cycles of disease or parasitism, and reduce competition for energy between adults and juveniles (Strathmann 1993). Pelagic dispersal also enables larvae to exploit the pelagic environment or avoid predation associated with benthic environments (Strathmann 1993). Organisms that utilize planktonic dispersal benefit from greater gene flow, larger home ranges, and greater interconnectivity between communities. On the other hand, local, or benthic dispersal provides for localized adaptation to community forcing functions, stronger links between adults and recruits but an increased vulnerability to disturbance and disease.

The majority of benthic species, however, utilize moderate dispersal distances on the order of tens of $\mathrm{m}$ (Strathmann et al. 2002). The production of dispersing recruits over a moderate distance exploits a type of "bet hedging," in that leaving a suitable site for adults, a recruit may find a better or worse recruitment site in a heterogeneous environment (Strathmann et al. 2002), excluding the possibility for mortality originating from adult conspecifics (e.g., filtration of potential recruits, [Andre and Rosenberg 1991]; defecation, and burial by adults, [Woodin and Marinelli 1991]). In a heterogeneous environment the chance of a recruit encountering a suitable site may be higher than in a more homogeneous environment, in part because a new recruit may require a diverse environment for growth and utilize a different spatial niche than the adult. In essence, larval behavior may have profound implications for long-term success.

The exploratory period, during which a new recruit explores the sediment surface through crawling or briefly burrowing, is important because predation and/or disturbance may remove the larva from a potentially good recruitment site. Site 
selection is critical because movement of many benthic individuals is limited once metamorphosis occurs. Although diverse environments may enhance the probability of success, factors influencing larval choice, (e.g., the physical and/or chemical environment) are often quite different from the factors affecting adult requirements. For example, environments high in ammonium deter newly recruiting arenicolids from burrowing (Woodin et al. 1998), but appear to attract adults (pers. obs.), perhaps due to an association of high ammonium with high productivity and food resources (Bianchi and Rice 1988).

\section{Recruitment and the Role of Physical, Chemical and Biological Processes}

Both large (on the order of hundreds of meters and greater) and small-scale (on the order of centimeters) physical forces affect recruit dispersal, delivery, and ensuing success. It is generally agreed that for larvae with planktonic dispersal, large-scale, dynamic physical processes in coastal and estuarine systems influence larval transport and distribution (Ekman 1967; Scheltema 1974; Levin 1986). The degree to which physical transport processes on smaller scales determine invertebrate settlement, however, is more controversial (Butman et al. 1988a, b; Ólafsson et al. 1994). Originally, patterns in larval distribution were thought to be solely a result of hydrodynamics and thus determined by the physics of deposition, entrainment, and random chance rather than active selection of suitable settlement sites by competent (actively settling into benthic environments) larvae (e.g., Eckman 1983). Studies supporting this idea of passive deposition of invertebrate larvae to soft-sediment 
environments reiterate that most larvae cannot swim at speeds comparable to local flow velocities, especially in turbulent flow (Eckman 1983, 1990). Small-scale turbulent flow in the benthic environment can be caused by sources of topographical heterogeneity such as roughness elements, (e.g., hummocks, feeding pits, and animal tubes), and can enhance deposition onto and erosion of soft sediment surfaces (Snelgrove and Butman 1994; Eckman 1979). For example, Huettel et al. (1996) and Rusch and Huettel (2000) have shown in permeable sediments that surface structures and small-scale differences in sediment height associated with ripples can influence fluxes of water and particles at depths of 4 to $8 \mathrm{~cm}$ beneath the sediment surface. Eckman (1983) found that structures such as worm tubes and seagrass shoots influence local hydrodynamics sufficiently to affect recruitment rates (via passive deposition), sediment deposition, and sediment composition.

On smaller scales (e.g., centimeters), behavior can enable certain species to move moderate distances, or to adjust their position and rate of movement, in the presence of a dynamic flow environment. For example, maximum horizontal swim velocities for the larval polychaete Capitella sp. I are approximately $3.5 \mathrm{~mm} \mathrm{~s}^{-1}$, and similar speeds have been found for other benthic larvae of the same size (Butman et al. 1988a). Natural flow speeds exceeding larval swim velocity exist a few body lengths above the sediment surface; thus larvae can swim up into the higher velocity region and use flow to migrate to another site. Deliberate timing of vertical swimming behavior can enable benthic organisms to travel appreciable distances with tidal currents (McEdward 1995) and against predominant flows within an estuary. Adult bay scallops, Agropectens irradians have been observed to use this method to migrate 
when community density is high and emigration is favored over competition (Powers and Peterson 2000). It has been found, however, that settling larvae often make recruitment decisions when flow is minimal, such as at slack tide, and avoid unnecessary energy expenditure (Gross et al. 1992).

There is now general agreement that recruitment patterns are affected by passive and active processes, operating at different temporal and spatial scales (Butman 1987). On small scales the effects of exploratory behavior and behavioral choice interacting with physical processes are important. It is most likely that recruitment success is a result of an increase in favorable opportunities arising from active settlement behavior in addition to the chance that passive deposition will place an individual into a suitable environment.

\section{Infaunal Recruitment Processes - The Chemical Environment}

Arguments for differential settlement patterns through active site selection have been associated with chemical cues in overlying waters, in porewaters, and at substrate surfaces (Pawlik 1992; Turner et al. 1994; Tamburri et al. 1996). For sediments, large-scale patterns in availability of oxygen are a major covariate of infaunal distribution (Thorson 1966; Pearson and Rosenberg 1978; Diaz and Rosenberg 1995). However, community-wide processes can also affect small-scale patterns as well. Through bioturbation and irrigation, infauna create very steep geochemical gradients over small spatial and short temporal scales (e.g., Marinelli 1994; Marinelli and Woodin 2002). In addition to geochemical effects, bioturbation can have both stabilizing and destabilizing effects on the sediment that can further 
influence recruitment choice: while biodeposition and the production of mucus are stabilizing, bioturbation and resuspension tend to destabilize sediment (Rhoads 1974). The result is a community characterized by significant lateral as well as vertical chemical heterogeneity.

Recent studies (e.g., Woodin et al. 1993, 1995, 1998; Marinelli and Woodin 2002) have shown that small scale variation in the chemical environment related to disturbance affects recruitment decisions of newly settled juveniles (new juveniles). Organic content and associated geochemical factors can also be important. For example, Butman and Grassle (1992), tested recruitment responses of Capitella sp. I to small patches $\left(16 \mathrm{~cm}^{2}\right)$ of a matrix of abiotic glass beads and organic-rich sediment and found consistent selection of organic rich sediment. They argued that repeated testing behavior by new recruits increased the possibility of an encounter with a suitable settlement site. A number of marine invertebrates, such as oysters (Fitt and Coon 1992), conchs (Rodríguez et al. 1995), and barnacles (Raimondi 1990) are attracted to elevated ammonium environments. While recruitment response to sulfides may be affected by other environmental conditions such as organic content (Dubilier 1988), Cuomo (1985) found that the polychaete Capitella also responds positively to increased $\mathrm{H}_{2} \mathrm{~S}$ concentrations. Work by Hardege et al. (1998) support the suggestion that active selection of sites with high concentrations of food (organic material) favor recruitment success. Given the high spatial variation in geochemical properties in sediments, and the strong relationships between organic matter content, diagenetic properties, and space, it is highly likely that local variation in recruitment patterns are strongly influenced by local geochemical processes. 


\section{Larval Recruitment Processes - Disturbance and Recruitment}

The sediment surface can be disturbed by diverse physical and biological processes, (e.g., surface scouring, wave action, feeding activities of benthic macrofauna or bottom feeding fishes, and sediment deposition from burrowing animals), operating on a wide range of spatial scales. Small-scale disturbances are of equal, if not of greater importance than low frequency, large scale disturbance events in shaping community diversity and function on longer temporal scales (Krager and Woodin 1993).

As a result of typical disturbances of moderate frequency and strength, the sediment surface is an ever-changing patchwork of communities in various stages of disturbance and recovery. Many of these sources of disturbance, (e.g., erosion of sediments through scraping, scour, or biodeposition), can be sources of mortality for new recruits and thereby prevent colonization. Conversely, established theories concerning moderate disturbance levels suggest that community diversity will be maximized in such environments due to the pre-emption of competitive exclusion (Dayton 1971; Connell 1978). Sutherland (1974) suggested that heterogeneity could provide increased community diversity and incorporate more functions with increasing environmental variability, because there are more niches that can be filled. In fact, increases in diversity have been observed in many ecosystems to lead to increased productivity (e.g., Tilman et al. 1997a).

Changes in the chemistry of surficial porewaters due to chemical properties and modifications imposed by infaunal activity and other forms of disturbance have 
been found to significantly impact recruitment decisions (Cuomo 1985; Woodin 1986, 1991; Marinelli and Woodin 2002). These observations have lead to the suggestion that organisms use chemical cues associated with disturbance to avoid sites where the probability of mortality is comparatively high. Perturbations on spatial scales comparable to larval sizes can provide a distinct signal. For example, concentrations of biologically important solutes such as $\mathrm{O}_{2}, \mathrm{H}_{2} \mathrm{~S}$, and ammonium can range by two orders of magnitude on spatial scales less than $2 \mathrm{~cm}$ in bioturbated sediments (Aller and Aller 1998).

Ammonium is a biologically active compound that is produced by decomposition of organic material and is ubiquitous in coastal environments. However, its concentration is affected by disturbances that are often linked to sources of juvenile mortality (Marinelli and Woodin 2004), and several species of infauna (e.g., Capitella sp. I) are known to avoid sediment surfaces characterized by elevated ammonium concentrations. While adult infauna may have mechanisms to cope with high ammonium concentrations, larval avoidance may be a physiological response to ammonium toxicity or an evolutionary response to disturbance. An important question is whether ammonium serves as a specific recruitment cue or if other processes associated with ammonium are involved in site rejection responses.

\section{My Study}

This study examines the coupled effects of geochemical, and physical processes on recruitment patterns in soft sedimentary environments. I developed a method for manipulating geochemistry by means of producing polyacrylamide gel 
diffusers with a known amount of specific solute and embedding the gels beneath a layer of sediment. This provided a predictable manipulation that mimicked chemical effects associated with disturbance while all other variables could be held constant. In previous studies, the recruitment response to disturbance effects has been integrated across a suite of environmental variables, confounding diagenetic processes, and hydrodynamics (e.g., Butman and Grassle 1992; Marinelli and Woodin 2002). The experiments described below clearly provide insights into the recruitment response of settling larvae in an environment characterized by a single, dominant chemical cue in a system that realistically simulates natural hydrodynamic conditions. By testing the recruitment behavior in the presence of flow, behavior that exploits hydrodynamic conditions (such as lifting appendages into the water column and swimming vertically) can be examined in a more realistic environment. Furthermore, by successfully manipulating a specific solute known to modify recruitment patterns, while keeping all other geochemical parameters the same, the recruitment response to the manipulated substrate can be clearly identified. The following null hypotheses were tested:

$\left(\mathrm{H}_{0}\right)$ : Experimental manipulation of sediment geochemistry will not produce a significantly different chemical environment.

$\left(\mathrm{H}_{0}\right)$ : In a hydrodynamic environment, recruiting individuals will not be differentially retained in geochemically-manipulated sediments 
The results from this study integrate biotic and abiotic processes involving recruitment behavior, small-scale geochemistry, hydrodynamics, and disturbance. To make ecologically valid interpretations of the results, the factors regulating recruitment must link physical attributes of the benthic boundary layer, and chemical characteristics of a biologically active sediment surface, to the overall process of recruitment. 


\section{Methods}

\section{PreliminaryTrials}

A series of experiments were initiated to determine the diffusive characteristics of acrylamide gels and their utility as a source of ammonium to surface sedimentary layers. Specifically I examined (1) the time course of diffusion of ammonium from a bare (no overlying sediment layer) gel to an overlying water column (the diffusive flux), using varying ammonium concentrations in gels; (2) the effect of sediment layer thickness on ammonium flux, and (3) the utility of ammonium persulfate vs. potassium persulfate as a crosslinking agent. This latter trial was initiated because the ammonium persulfate was a significant ammonium source and a "no-ammonium" control was needed. Polyacrylamide gels were made according to Browne and Zimmer (2001) with acrylamide concentrations ranging from $8-15 \%\left(\mathrm{~N}, \mathrm{~N}^{\prime}\right.$-methylene-bis(acrylamide), w/v, final). For most experiments, crosslinking of the acrylamide gel was initiated with $0.05 \%$ ammonium persulfate (APS; w/v, final) and catalyzed with $0.05 \%$ tetramethylenediamine (TEMED; v/v final). Potassium persulfate (KPS) was substituted for ammonium persulfate (APS) in the potassium persulfate trials. In both cases, polymerization occurred in less than $1 \mathrm{~h}$. These trials are described below:

\section{A. Diffusion Experiments}

To characterize the time course of ammonium release from bare gels to overlying waters, and to test the effect of ammonium concentration within gels on the 
flux, diffusion experiments were carried out with gels containing 3 different ammonium concentration spikes: 0,500 , and 2,000 $\mu \mathrm{M}$ ammonium. Ammonium spikes were accomplished by addition of ammonium sulfate to distilled de-ionized (DDI) water. For each concentration, 3 replicates were prepared, each consisting of $100 \mathrm{ml}$ of gel poured into $250 \mathrm{ml}$, sterile specimen containers and allowed to set. Subsequently, $100 \mathrm{ml}$ of DDI water was gently pipetted on top of the gel to create an overlying water (OLW) column of $4 \mathrm{~cm}$, and allowed to incubate for $300 \mathrm{~min}$. The OLW was stirred every 15 min to maintain a well-mixed water column and to prevent the buildup of a solute gradient in the water column and prevent feedback between water column concentrations and the acrylamide gel. At 60-min intervals, $3 \mathrm{ml}$ samples were collected, filtered ( $0.2 \mu \mathrm{m}$ filters $)$ and placed in sterile containers. The samples were then refrigerated until analysis for ammonium concentration, usually within $48 \mathrm{~h}$, according to the method of Koroleff (1976). Flux is a measure of mass (m) per unit area (A), or length squared, per unit time ( $t$, Equation 1). Since concentration of a solute is measured as mass per unit volume, or mass over length cubed, flux can thus be measured by multiplying concentration (C) by water column height (L), divided by time ( $t$, Equation 2).

$$
\begin{aligned}
& \text { Flux }=m /\left(\mathrm{A}^{*} t\right) \\
& \text { Flux }=\mathrm{C} * \mathrm{~L} / t
\end{aligned}
$$


The flux of ammonium across the gel surface was calculated by linear regression (Fig. 1) of change in concentration (C) vs. time ( $t$ ), normalized to the height of the water column (L). Since flux is assumed to be constant during the observed time period, I assumed a linear relationship between time and water concentration. Preliminary experiments suggested that a linear ammonium response was appropriate for this experimental interval (Fig. 1).

To test the effect of sediment layer thickness on ammonium flux from gels, a second set of experiments was conducted using 2,000 $\mu \mathrm{M}$ acrylamide gels topped with sediments of varying thickness. For these experiments, gels were created with a higher concentration (15\%) of acrylamide, which produced a firmer layer for support of the sediment column. I used the same setup as in the previous experiment but with $50 \mathrm{ml}$ of gel. Sediment consisted of seawater-soaked ( $>24 \mathrm{~h}$ ), moderately sorted (mean grain size $=287 \mu \mathrm{m}$ ) store-bought sandbox sand (from here referred to as play sand) that was gently placed on top of the gel to achieve a thickness of either 1 or 3 $\mathrm{cm}$. Two controls were attempted: a bare gel (no sediment cover) and a gel covered with a plastic disk (to prevent diffusion) overlain by $1 \mathrm{~cm}$ of sediment. Approximately $150 \mathrm{ml}$ of DDI water was added to produce a water column $5.5 \mathrm{~cm}$ in height. Four replicates were used for each treatment. The sampling/stirring regime was similar to that described for the previous experiment.

Gels produced with no-ammonium DDI water solutions released substantial concentrations of ammonium due to the ammonium persulfate (APS) crosslinker (see results). While this is advantageous for having an ammonium source, it presents a 


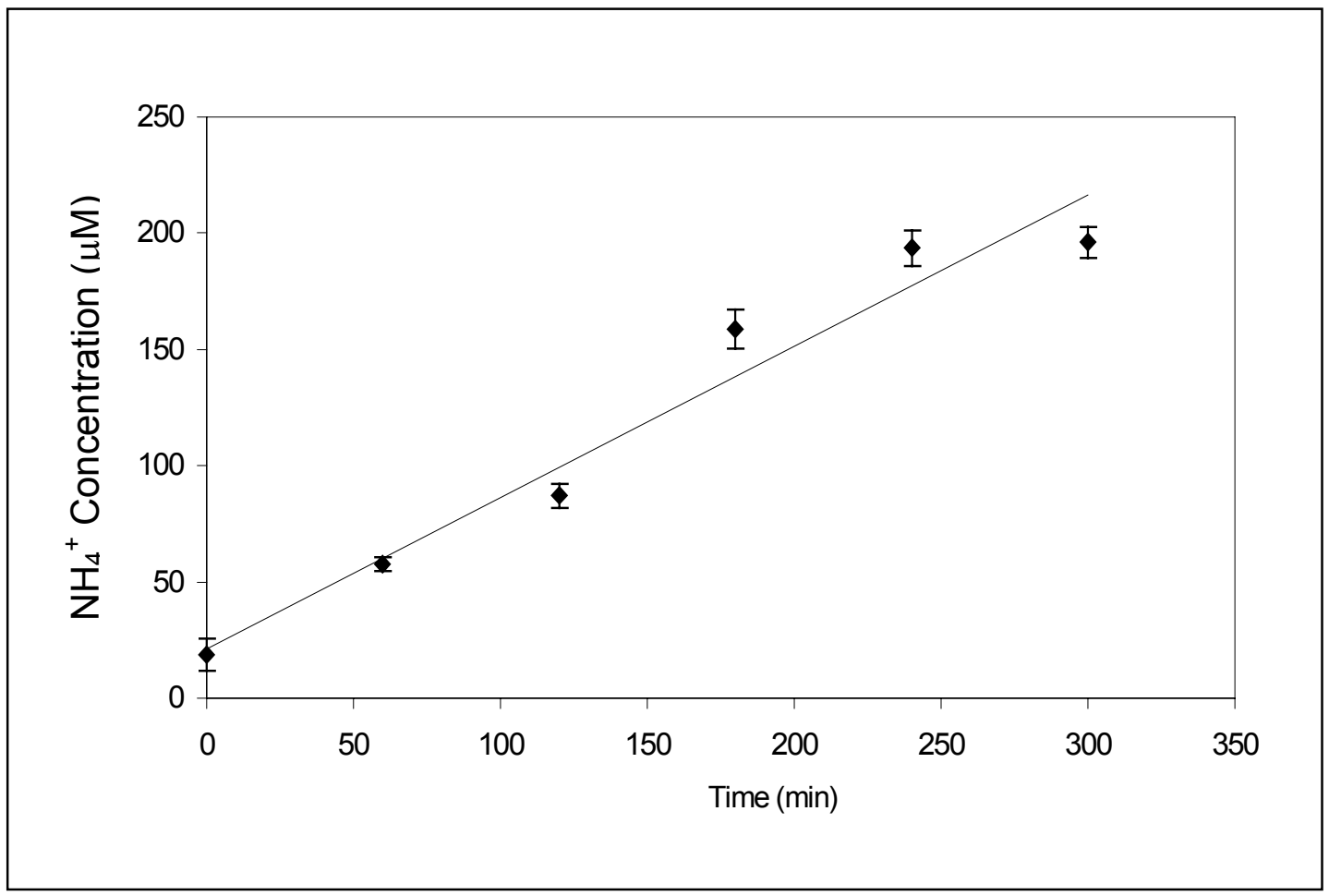

Figure 1. Change in overlying water $\mathrm{NH}_{4}{ }^{+}$concentration over time in bare gel (no sediment) experiments using 2,000 $\mathrm{MM} \mathrm{NH}_{4}^{+}$spiked APS gel. Samples taken every $60 \min (n=3)$. Regression fit to a linear function $\left(\mathrm{F}=199.02, \mathrm{R}^{2}=0.9549, p<0.001\right)$. 
difficulty for establishing a "no ammonium" gel control. A preliminary trial was conducted to test the utility of using potassium persulfate (KPS) as a cross-linking agent. APS (0.05\%) gels were made with DDI water (no added ammonium sulfate) or 2,000 $\mu \mathrm{M}$ ammonium sulfate-spiked DDI; KPS (0.05\%) gels were made in DDI water with no added ammonium. Approximately $50 \mathrm{ml}$ of gel were poured into each container to which $135 \mathrm{ml}$ of DDI water was added after the gels had set. The OLW was stirred every $30 \mathrm{~min}$. Filtered $(0.2 \mu \mathrm{M})$ overlying water samples were taken at 0 , 105,280 , and $380 \mathrm{~min}$, stored and analyzed as described above. Due to low variance in flux rates observed from prior experiments, only 3 replicates were prepared for each treatment.

Acrylamide gels produced with KPS took slightly longer to set but had the same consistency as APS gels. Flux of ammonium out of the KPS gels was negligible, while significantly higher flux rates were found for the $0 \mu \mathrm{M}$ and 2,000 $\mu \mathrm{M}$ treatments containing APS (Fig. 2), (analysis of variance: $\mathrm{F}_{3,2}=832.69$, $p<0.0001)$. Acrylamide gels made with KPS, however, were not used in further tests because concentrations of potassium added by KPS (here calculated to be $0.0037 \mathrm{M}$ ) were similar in magnitude to natural potassium concentrations in seawater $(0.01 \mathrm{M}$, Burton 1976). The presence of $\mathrm{K}^{+}$in elevated concentrations could affect vital functions, such as chemoreception, of settling juveniles. As a result, controls procedures were modified to consist of sediment only or sand placed on top of gels with no incubation time (see below). 


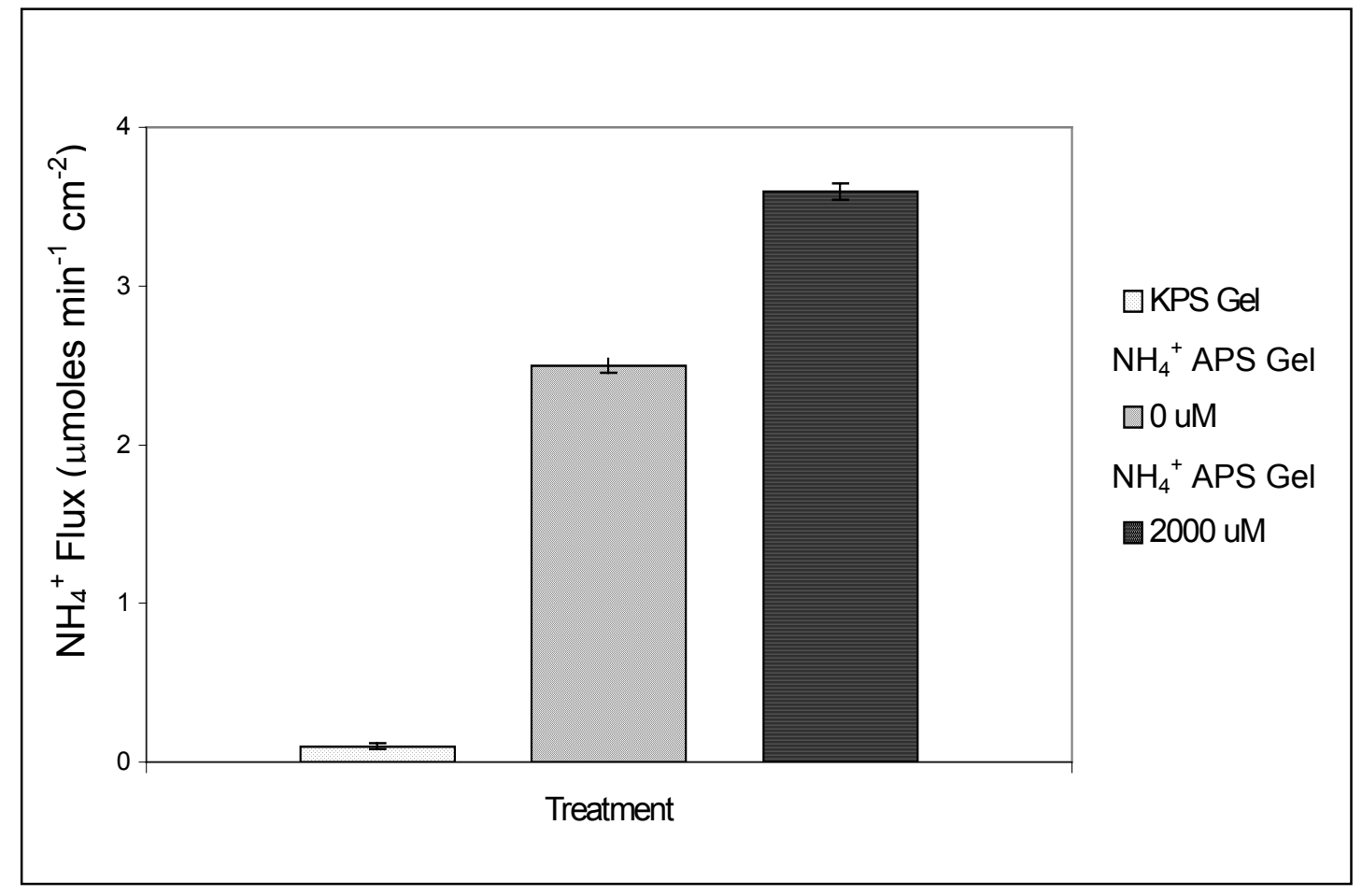

Figure 2. Flux of $\mathrm{NH}_{4}{ }^{+}$from bare (no sediment) acrylamide gels produced with ammonium persulfate (APS) and potassium persulfate (KPS). The KPS and $0 \mu \mathrm{M}$ $\mathrm{NH}_{4}{ }^{+}$APS gels were produced with no ammonium sulfate, the third treatment was produced with a $2,000 \mu \mathrm{M}$ ammonium sulfate solution. Bars are mean values \pm one standard deviation, all $\alpha$ values set at $0.05, \mathrm{n}=3$ for all treatments. 


\section{B. Initial Tests of Mercenaria and Arenicola Responses to Ammonium - "Sandwich" Flume Experiments}

In these experiments, I examined the response of organisms to chemically manipulated sediment surfaces in a fluid dynamic environment. New juveniles were added to experimental cores containing acrylamide gels overlaid with a thin $(1 \mathrm{~cm})$ sediment layer. Initiation of flow after an exploratory period would allow migration of juvenile individuals from unacceptable habitats. Thus, differences among retention of new juveniles as a function of treatment would indicate an effect of ammonium on habitat choice in flow.

\section{i. Test Organisms}

I chose to use Arenicola cristata and Mercenaria mercenaria because they are ecologically and/or economically important species with a cosmopolitan distribution along the eastern shore of the United States. The polychaete Arenicola cristata is a subsurface deposit feeder that serves as a food source for many benthic feeders, including commercially important demersal fish. The bivalve Mercenaria mercenaria (hard clam) is an economically valuable species that brings in roughly 30 60 million dollars annually to the US economy (National Marine Fisheries Service, 2003). These two species represent a small sampling of benthic infauna, but both have a dispersal phase and must return to benthic habitats similar to those from where they were released.

Egg-cases of the infaunal polychaete Arenicola cristata were collected from Bly Creek in the North Inlet estuary, Georgetown, South Carolina ( $79^{\circ} 09^{\prime} \mathrm{W}, 33^{\circ} 19^{\prime}$ 
N) in April, 2001. The gelatinous mass was maintained in aerated seawater in the lab and upon release, the larvae were transferred to smaller glass dishes. After approximately $7 \mathrm{~d}$, the larvae had grown to six setigers (roughly $600 \mu \mathrm{M}$ ). At this stage, individuals (new juveniles) will burrow into sediments and begin to build tubes (Woodin et al. 1995). Larval Mercenaria mercenaria were obtained from SeaPerfect Aquafarms, Charleston, SC. The cultures were kept in aerated seawater and fed Isochrysis galbana. Depending on temperature, larval Mercenaria will lose the velum and adopt a benthic existence approximately 10-20 d after spawning. Only organisms that had lost the velum (new juveniles) were selected for experiments. To ensure that the individuals were competent to burrow, and that the test sediment was acceptable to the new juveniles, preliminary "acceptability" tests were performed on six setiger arenicolids and Mercenaria that had lost the velum. The new juveniles were carefully pipetted onto field-collected sediment (obtained from Bly Creek, SC) and aged play sand (soaked in aerated, oxygenated seawater for $48 \mathrm{~h}$ ), and their exploratory and burrowing behaviors were observed through a dissecting microscope. In particular, the time spent exploring the surface prior to initiation of burrowing was quantified. Previous observations have indicated that short exploratory times, and rapid burrowing, are indicative of an acceptable habitat, whereas long exploratory times, or failure to burrow, is taken as rejection of the habitat (Woodin et al. 1995; Marinelli and Woodin 2002). The observation period was 6 min (Woodin et al. 1998). Preliminary observations indicated that both Arenicola and Mercenaria juveniles burrowed into aged play sand and field sediments within short time frames (less than 1 min. for 4 out of 7 individuals of each species tested), as observed in 
acceptable sediments in previous studies (Woodin et al. 1998; Marinelli and Woodin 2002).

\section{ii. Description of flume}

The sandwich flume was a gravity-fed, non-recirculating, straight channel (Woodin et al. 1995) having dimensions of $1.26 \mathrm{~m}$ by $10 \mathrm{~cm}$. Water flow was facilitated by a header tank kept at constant volume and was regulated by a control valve. Water entering the working section passed through 'straighteners' (a hexagonal matrix of straws), which helped smooth water flow. A circular hole (diameter $5.8 \mathrm{~cm}$ ) in the working section $75 \mathrm{~cm}$ downstream allowed placement of cores into the flume such that core surfaces were flush with the flume bottom. For all trials, the flume was filled to a depth of $1.8 \mathrm{~cm}$.

\section{iii. Preparation of experimental cores}

Results of preliminary trials (below) indicated that $12 \%$ acrylamide gels made with ammonium persulfate provided a source of ammonium to the overlying water. When incubated for $6 \mathrm{~h}$ with a thin $(1 \mathrm{~cm})$ sediment over-layer, ammonium concentrations in the porewater created a distinct surface signature (mean ammonium concentration $414 \pm 78 \mu \mathrm{M})$. At the same time, gels that were covered with fresh sediment but allowed no incubation time had very little ammonium (mean ammonium concentration $30 \pm 69 \mu \mathrm{M})$ at the sediment surface. Thus, the addition of ammonium sulfate, and the presence or absence of an incubation period, allowed the establishment of 3 treatments: Low ammonium $(0 \mu \mathrm{M}$ ammonium sulfate gel with 1 $\mathrm{cm}$ sediment and no incubation period), Intermediate ammonium ( $0 \mu \mathrm{M}$ ammonium 
sulfate gel with $1 \mathrm{~cm}$ sediment and $6 \mathrm{~h}$ of incubation time); and High ammonium (6,000 $\mu \mathrm{M}$ ammonium gel with $1 \mathrm{~cm}$ of sediment and a $6 \mathrm{~h}$ incubation time). For these experiments, acrylamide gels were made with artificial seawater (DDI water with Instant Ocean salts) with addition of ammonium sulfate to the desired concentration level.

Approximately $60 \mathrm{ml}$ of acrylamide gel were poured into each experimental core. Cores consisted of a plexiglass annulus (inner diameter $=5.8 \mathrm{~cm}$; height $=4 \mathrm{~cm}$ for the low, and $8 \mathrm{~cm}$ for the medium and high), with a removable plunger (a solid PVC disk with 2 O-rings). After the gels had set, $0.75 \mathrm{~cm}$ of aged play sand was added to all Intermediate and High ammonium cores, followed by addition of $100 \mathrm{ml}$ of $3 \mu \mathrm{m}$-filtered seawater (salinity of $25 \mathrm{psu}$ ). These cores were allowed to equilibrate for at least $6 \mathrm{~h}$. At the conclusion of the incubation period for Intermediate and High Ammonium cores, the overlying water was removed and replaced 4 times with fresh, $3 \mu \mathrm{m}$-filtered natural seawater. For the Low Ammonium cores, a small amount of artificial seawater was added to the surface of the uncovered gel to keep it moist. Immediately before use in flume trials, the water was removed and a layer of aged sand was added to match the thickness in the medium and high cores.

Subsequently, seawater was added and replaced as in the Intermediate and High Ammonium cores. For all cores, the water column height just prior to flume trials was $2 \mathrm{~cm}$.

\section{iv. Experimental protocol}

Because flume experiments could involve only one core at a time, trials were run in blocks, with each block containing a low, medium, and high core trial, 
randomly distributed, for a total of 8 experimental blocks. For each of the medium and high trials, filtered samples $(0.2 \mu \mathrm{m},<1 \mathrm{ml})$ of the overlying water (OLW) column were taken to establish ammonium concentrations immediately after placement of the core in the flume bed but prior to the addition of new juveniles. Since there was little OLW for the low ammonium trial, no sample was taken prior to adding new juveniles.

For each trial, competent (as described above), new juveniles (75 Arenicola and 50 Mercenaria) were collected and transferred to a small holding dish containing $20 \mathrm{ml}$ of $3 \mu \mathrm{m}$-filtered seawater. An experimental core was inserted into the bottom of the drained flume so that the water column of the core was just below the flume bottom surface. The dish containing both species of new juveniles and a small volume of water was gently transferred to the overlying water of the core, such that no disruption of the sediment surface, and no overflow of water onto the flume channel occurred. The new juveniles were then allowed to settle in still water for 5 to $7 \mathrm{~min}$. Subsequently a sample of the overlying water in the core was taken to determine if water column ammonium concentrations changed as a result of the new juvenile addition process. The sample was filtered through a $0.2 \mu \mathrm{m}$ filter, transferred to a clean vial, and refrigerated prior to analysis.

Subsequent to addition of organisms, flow was initiated and the flow speed was adjusted to $3.0 \pm 0.5 \mathrm{~cm} \mathrm{~s}^{-1}$. This flow speed was chosen because it represents hydrodynamic conditions found in environments inhabited by the studied species. Once flow was established, the core plunger was gently pushed upward until the sediment surface was flush with the flume bottom. The sediment surface was 
exposed to flow for $3 \mathrm{~min}$. Flow was turned off, the flume was then drained, and a porewater sample $(<0.7 \mathrm{ml})$ was taken from the top $0.5 \mathrm{~cm}$ of sediment, using a syringe fitted with a 16 gauge needle. The sample was filtered $(0.2 \mu \mathrm{m})$, transferred to a clean vial, and refrigerated. The entire $0.75 \mathrm{~cm}$ layer of sediment on the gel surface was removed, preserved with buffered formalin, and stained with Rose Bengal for subsequent enumeration of juveniles. The process was repeated eight times for each of 3 treatments.

\section{v. Analysis}

Water samples were taken back to the Chesapeake Biological Laboratory and analyzed for ammonium within $5 \mathrm{~d}$ as previously described. The sediment samples were transferred from a formalin solution to ethanol and then sorted using an Olympus SZH-10 zoom dissecting scope to determine the number of Arenicola and Mercenaria juveniles remaining in the sediment. Differences in ammonium concentration data were analyzed by analysis of variance using SAS v8.0 (SAS Institute, Cary, NC, 1999). Retention of new juveniles onto the manipulated sediment surface (count data) was considered to be nonparametric because values range from 0 to 1.00 as proportions. Because the count data were treated as proportional, the data

were transformed using an arcsin function and then analyzed with ANOVA. Analysis of the residuals and the homogeneity of variance of the parametric ANOVA indicated that the data were non-normally distributed. Consequently, the data were analyzed using a Jonckheere-Terpstra nonparametric ordered alternatives test, where an observed response is evaluated relative to a predicted response, and where deviation from the null hypothesis is expected in a particular direction (Hollander and Wolfe 
1973). In this experiment, I predicted that retention rates would be higher in low ammonium sediments, and lower in high ammonium sediments.

\section{Hydrodynamic Characterization of Annular Flume}

A second set of experiments testing Mercenaria and Arenicola responses to ammonium-spiked sediments was conducted using an annular flume (Fig. 3). Due to differences in the timing of new juvenile availability, separate trials for each species were run. The flume (see Porter 1999 for a more detailed explanation) consisted of a circular (180 cm outer diameter) channel $20 \mathrm{~cm}$ wide and $20 \mathrm{~cm}$ deep. The channel flow was driven by contact on the water surface with a plexiglass ring $10 \mathrm{~cm}$ across, thus covering half of the channel width. The ring was attached to a rigid support system driven by a variable speed DC motor. Six removable resin-coated wood and fiberglass trays were made to fit snugly into the flume on the bottom of the channel. The trays measured $18 \mathrm{~cm}$ across with walls approximately $3-4 \mathrm{~cm}$ high. Each tray was subdivided into 3 equal $\left(430 \mathrm{~cm}^{2}\right)$ sections by two plastic walls $3 \mathrm{~cm}$ high, giving a total of 18 subsections. The subsections held a volume of approximately $2 \mathrm{~L}$ and were used to accommodate acrylamide gels of varying ammonium concentration. Of the 18 subsections, either 6 (Mercenaria experiment) or 9 (Arenicola experiment) subsections were assigned as test sections and the remainder were not used. All 


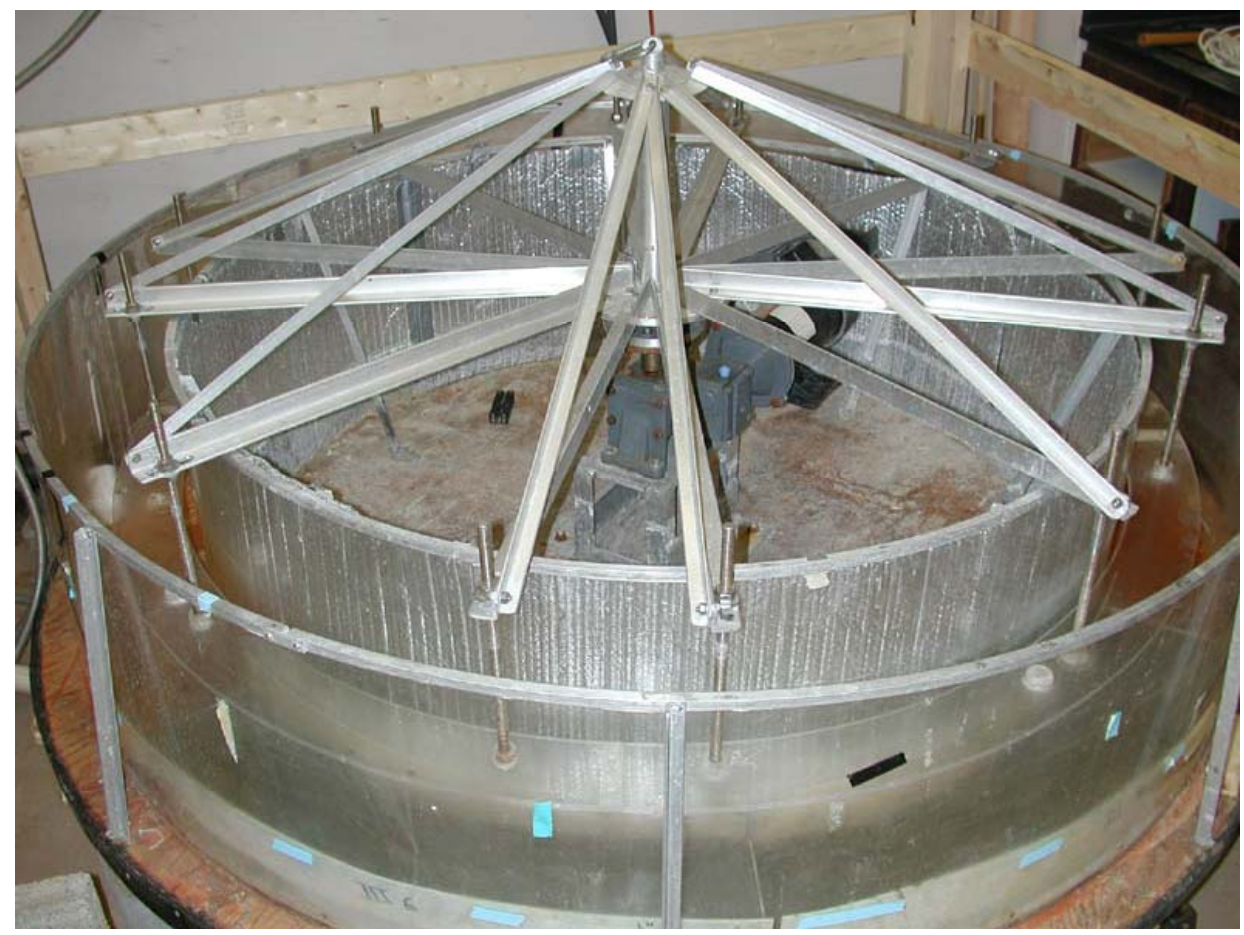

Figure 3. Photograph of the annular flume (180 cm outer diameter) at the Chesapeake Biological Laboratory. Flow is controlled by a DC motor (center), which drives the ring support struts in a circular motion. 
subsections were arranged to alternate between test sections and unused sections, so that no two test sections were directly adjacent to one another in the flume (Fig. 4). To characterize the fluid dynamic environment, velocity profiles were measured with a SonTek Micro ADV (acoustic Doppler velocimeter). The flow profiles were measured at $15 \mathrm{~cm}$ from the inner wall of the flume channel (channel width $=20 \mathrm{~cm}$ ), rather than $10 \mathrm{~cm}$ from the inner wall (center of channel) due to the position of the driving ring. Profiles were measured at a ring speed of $4.5 \mathrm{RPM}$, at $1 \mathrm{~mm}$ intervals above the sediment surface to $12 \mathrm{~mm}$, and at $3 \mathrm{~mm}$ intervals until freestream velocity was reached (Fig. 5). The position of the ADV and sample volume was controlled with a micromanipulator. The height of measurement above the sediment water interface was determined using a combination of measurements of the signal-to-noise ratio and a direct measurement of the ADV probe tip above the sediment surface, according to Finelli et al. (1999).

Several lines of evidence suggest that the flow velocities within the flume did not result in bedload resuspension or advection of solutes out of sediment porewaters. Advection of porewaters can arise from pressure differences driven by surface gravity waves or topographical variation in the sediment surface (e.g., Huettel et al. 1996). Since flow within the flume was smooth and relatively free of secondary circulation artifacts $(<7.2 \%$ secondary circulation, see results), and the bed was smoothed prior to each trial, pressure differences at the sediment surface were minimal. To qualitatively assess the importance of advection of porewaters out of the test sediments, rhodamine WT dye was added to wet sediment and then placed in the annular flume and smoothed. The sediment surface was observed for release of dye 


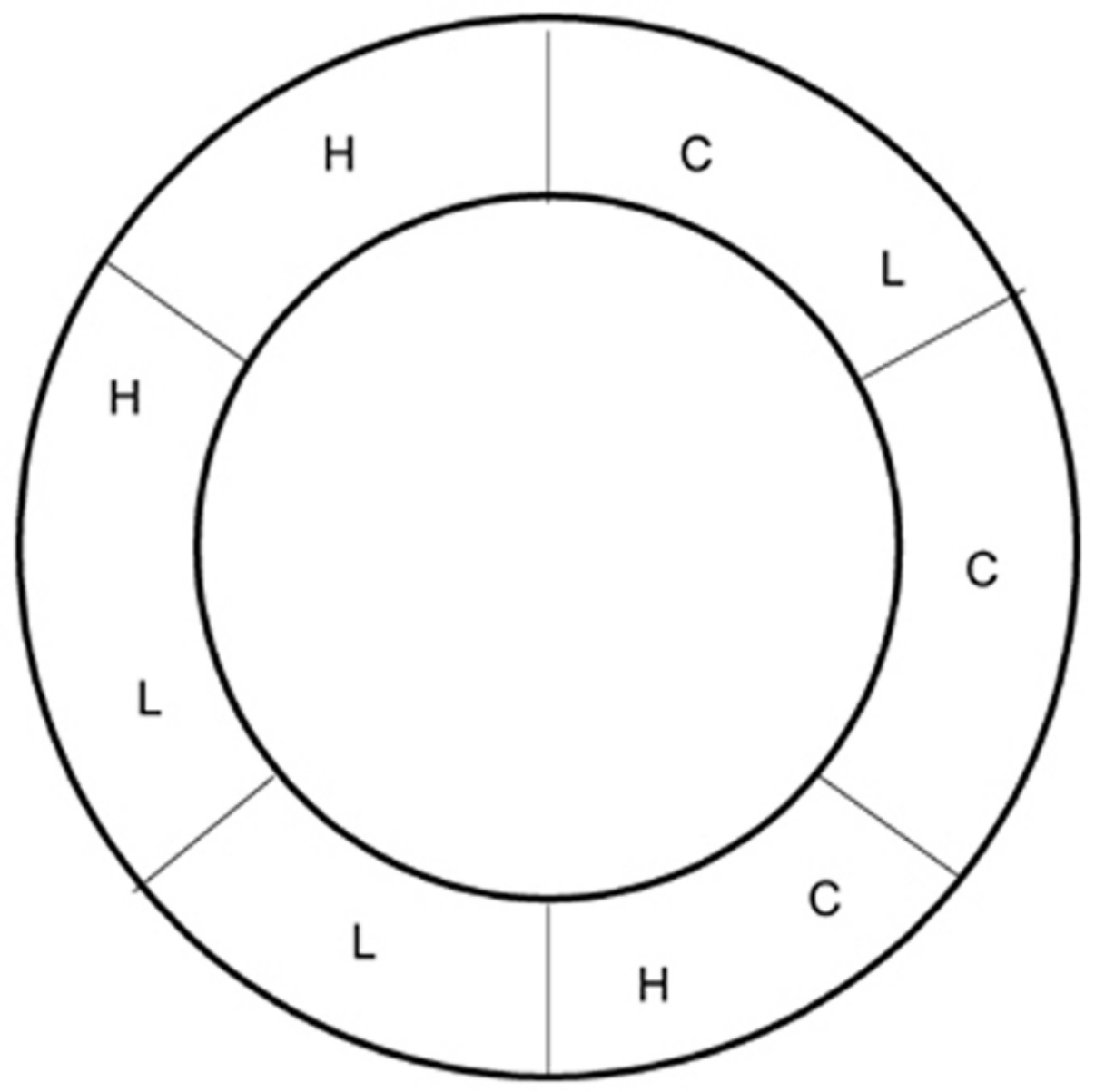

Figure 4. Diagram of the sections and treatment subsection setup within the annular flume. For the Arenicola experiment, three replicates of each treatment (Control, Low, and High) were randomly assigned to test subsections. For all trials, flow was in a clockwise direction. Flume dimensions (diameter $=180 \mathrm{~cm}$, channel width $=20$ $\mathrm{cm}$, water column height $=15 \mathrm{~cm}$ ) were held constant for all trials. Diagram not drawn to scale. 


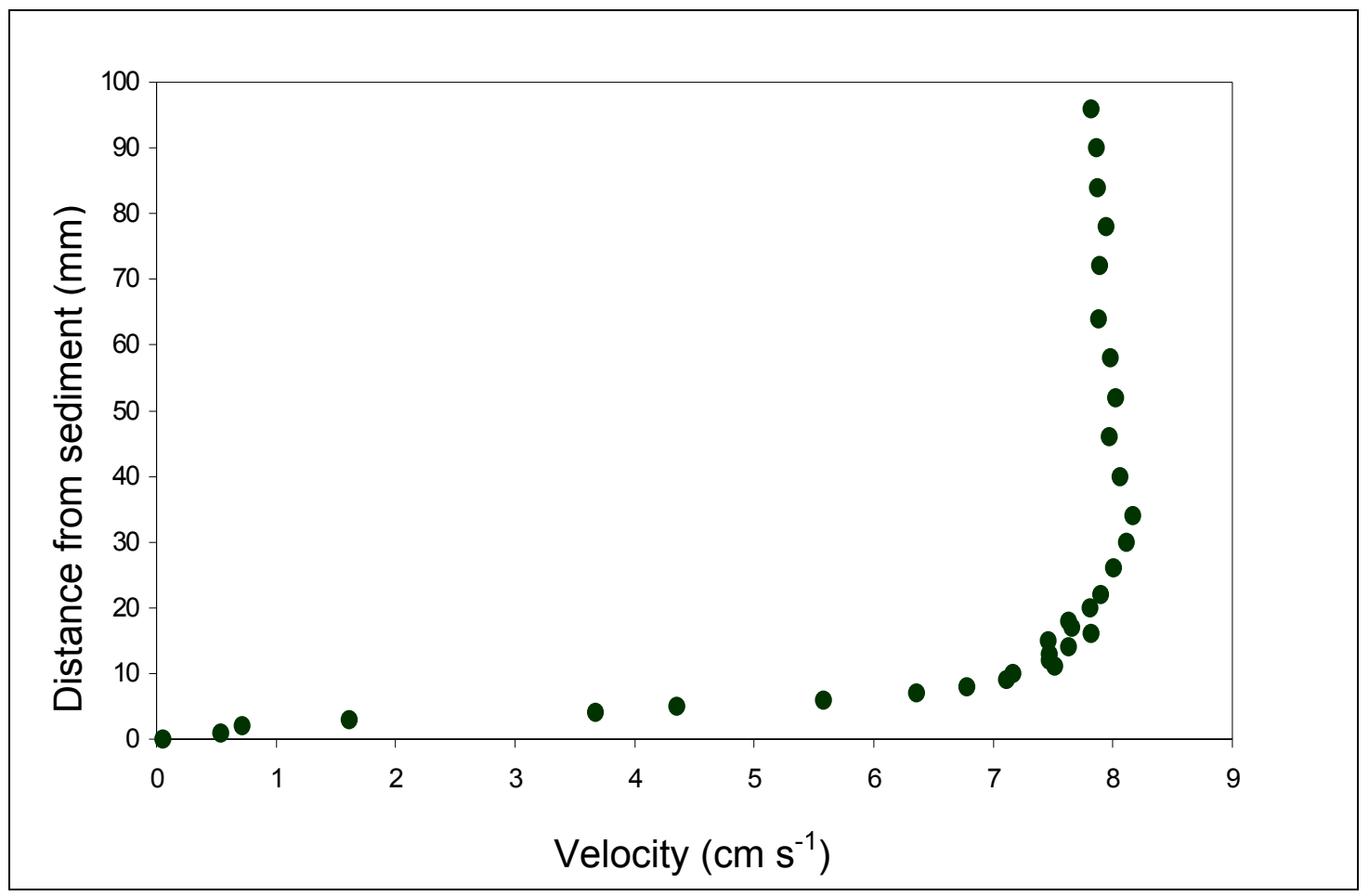

Figure 5. Velocity profile above the sediment water interface (SWI) at ring speed 4.5 RPM as measured by a SonTek ${ }^{\circledR}$ MicroADV. Measurements taken every $1 \mathrm{~mm}$ below $12 \mathrm{~mm}$ from SWI, and every $3 \mathrm{~mm}$ above $12 \mathrm{~mm}$, with vertical position controlled by micromanipulator. Mean freestream velocity calculated to be $7.79 \pm$ $0.21 \mathrm{~cm} \mathrm{~s}^{-1}$. 
during normal flow. Very little dye was released from the sediment surface, suggesting that advection was not occurring. Similarly, no significant bedload transport was observed at the ring speed used in the experiments. Although advection was only qualitatively observed and not quantified, I felt that the obtained information from these observations indicate an environment in which porewater advection was minimal. Furthermore, these observations, and high ammonium measured within the bed but low ammonium within the water column (see below), suggest advective processes did not control porewater flow and that current velocities did not erode particles.

Field sediments used in the annular flume experiments were collected from Tom's Cove, VA $\left(73^{\circ} 23^{\prime} \mathrm{W}, 37^{\circ} 56^{\prime} \mathrm{N}\right)$ and had been sieved $(500 \mu \mathrm{m})$ and stored in running seawater (see below). Grain size distribution of both field sediments and play sand (determined according to Folk and Ward, 1957) were similar (mean grain size $=290 \mu \mathrm{m}$ and $287 \mu \mathrm{m}$ ) with sediment types categorized as well to moderately sorted (Std. dev. $=0.5987$ and 0.7289$)$, medium sands tending toward coarser grains (skewness $=0.1970$ and -0.0389 ) for field sediment and play sand, respectively. Thus, both sediment types were physically similar and likely to have similar effects on the hydrodynamic environment near the sediment-water interface.

\section{Diffusion in Annular Flume}

To determine whether ammonium buildup in the flume water column occurred when gels were embedded in trays, several preliminary flux tests were conducted. Two acrylamide gel solutions were made; one with a 2,000 $\mu \mathrm{M}$ ammonium solution 
at a salinity of 28 psu and one with filtered $(3 \mu \mathrm{m})$ seawater with a salinity of $28 \mathrm{psu}$ and no added ammonium. The control gel $(750 \mathrm{ml})$ was poured into a downstream subsection of a test tray, and the $2,000 \mu \mathrm{M}$ gel was poured $(750 \mathrm{ml})$ into the upstream section of the same test tray. Once the gels had set, $1.5 \mathrm{~cm}$ of play sand was added on top and smoothed with a trowel. All remaining upstream sections were filled with play sand (no gel) and the entire bed was smoothed. The flume was then filled with $22^{\circ} \mathrm{C}$, seawater with a salinity of $28 \mathrm{psu}$ to create a water column $15 \mathrm{~cm}$ high (roughly a total of $150 \mathrm{~L}$ ) and allowed to equilibrate for $5 \mathrm{~h}$ in still water. Water column samples were taken roughly $10 \mathrm{~cm}$ above the sediment water interface, within the $2,000 \mu \mathrm{M}$ gel treatment sections, filtered, and stored as previously described. The flume was drained until the water level was flush with the sediment surface. Porewater samples (filtered $0.2 \mu \mathrm{m}, 1 \mathrm{ml}$ ) were taken as described for the 3 different substrates within test trays (no gel below sediment, 2,000 $\mu \mathrm{M}$ below sedimen,t and $0 \mu \mathrm{M}$ gel below sediment). The flume was then refilled with seawater and another water column sample was taken and processed as described previously. The flume was then turned on at a speed of 7 to $8 \mathrm{~cm} \mathrm{~s}^{-1}$ (4.5 RPM) for $2 \mathrm{~h}$. A post-flow water column sample was taken, the flume was drained, and post-flow porewater samples were taken, as described previously. This process was repeated once more after the flume ran for an additional $2 \mathrm{~h}$ at $4.5 \mathrm{RPM}$. Sampling before and after flow established if ammonium concentrations were affected by the addition of water to the flume channel, the flow, and the presence of the treatments. No significant change in concentration was observed in the overlying water across all flume refills $\left(\mathrm{F}_{1,2}=0.368\right.$ $\mathrm{p}>0.05$ ) over a $2 \mathrm{~h}$ interval, thus accumulation of ammonium in the water column was 
negligible. This suggests that water column ammonium affects on juveniles due to the flume filling process was unlikely. Although higher gel concentrations were used for recruitment trials, the duration of the experiment was shorter and appreciable buildup did not occur (see results).

\section{Annular Flume Trials}

The seawater used in annular flume experiments was filtered water from the Patuxent River, MD, USA (salinity of $13 \mathrm{psu}, 18^{\circ} \mathrm{C}$ ), brought to room temperature and raised to a salinity of $21 \mathrm{psu}$ (Mercenaria experiment) or $28 \mathrm{psu}$ (Arenicola experiment) with Instant Ocean salts (Aquarium Systems, Inc.). The water was aerated and stored in a tank $(\sim 150 \mathrm{~L})$ until the start of the experiment. The experimental sediments consisted of a mixture of field-collected sediment (from an intertidal location at Tom's Cove, VA, $73^{\circ} 23^{\prime} \mathrm{W}, 37^{\circ} 56^{\prime} \mathrm{N}$ ) that had been sieved $(500 \mu \mathrm{m})$ and stored in running seawater, and play sand (as in previous trials). One d prior to each trial $20 \mathrm{~L}$ of field sediment was rinsed with prepared seawater 3-4 times. Similarly, the play sand was rinsed 3 to 4 times with prepared seawater. Just prior to each trial both sediment types were rinsed 2 to 3 times. Rinsing alleviated high ammonium concentrations that evolved during sediment storage.

\section{A. Mercenaria Experiments}

Larval Mercenaria mercenaria were obtained from Cherrystone Aqua-farms, Cheriton, VA ( $8 \mathrm{~d}$ old). Cultures were fed Isochrysis galbana and monitored 
continually to determine when the transition from a swimming to a benthic form (loss of velum) occurred. Individuals that had shed the velum (new juveniles) and were actively moving by use of their foot were counted ( 50 per experimental replicate) and separated into holding dishes. Before the trials, new juveniles were assessed for burrowing times and sediment-acceptability as done in the sandwich flume experiments previously described. Preliminary sediment-acceptability tests indicated that unmanipulated field sediment provided a suitable settlement environment. Of the 10 representative individuals tested, all burrowed in less than $2 \mathrm{~min}$.

Due to the time required to sort competent Mercenaria new juveniles, only 6 experimental replicates of two treatments (Low and High ammonium) were completed for each trial. Three replicates of each treatment were randomly assigned to the test sections within the flume. The treatments consisted of two acrylamide (12\%) gel concentrations $(0 \mu \mathrm{M}$, and $6,000 \mu \mathrm{M})$. The gels were poured into each section (approximately $2 \mathrm{~cm}$ deep) and allowed to set for at least $8 \mathrm{~h}$. Once set, the trays were put into the flume. The trays without gels were filled with $4 \mathrm{~cm}$ of play sand whereas the test sections were filled with $2 \mathrm{~cm}$ of play sand. Then, the entire flume bottom surface was covered with approximately $1.0 \mathrm{~cm}$ of field sediment. All seams between trays, sections, and the wall of the flume were smoothed with a trowel so that no obstructions to flow occurred. The flume was then slowly filled with prepared seawater to a depth of $4 \mathrm{~cm}$ and allowed to equilibrate for a minimum of $6 \mathrm{~h}$, to allow ammonium to diffuse toward the sediment surface. After the equilibration time, an overlying water column sample was taken from the flume ("pre-organism addition OLW"), and then the water was drained to the same level as the sediment 
surface. One porewater sample (pre-organism addition PW) was taken near the center of the test subsections. The flume was then filled to a depth of $4 \mathrm{~cm}$.

To add new juveniles to the test sections, plastic cylinders $(6 \mathrm{~cm}$ diameter, 9 $\mathrm{cm}$ high) were gently placed onto the sediment surface at the center of each test section (Fig. 6A). Individuals from the holding dishes were then gently pipetted into the water column within the plastic cylinders, using a minimal amount of water so that a large pressure head was not established. Sediment was not resuspended during the addition phase. The flume was slowly filled until the water height outside and inside the cylinders was equal. The cylinders were then removed and the water column was raised to a height of $15 \mathrm{~cm}$ (Fig. 6B). A sample of the water column was taken for analysis of ammonium concentration. The dishes that held the new juveniles were later checked under a dissecting scope for any Mercenaria remaining, i.e., that were not added to the test sediment.

Once the flume was filled, flow was initiated and maintained for $8 \mathrm{~min}$. This time period is approximately 10 times the average observed exploration time for new recruits of several bivalve and polychaete species prior to burrowing in acceptable sediments (Marinelli and Woodin 2002 and references therein). It therefore provided sufficient time for evaluation of sediment-acceptability and movement away from the site if sediments were deemed unacceptable. At the conclusion of the flow period, a water column sample (for ammonium analysis) was taken, and the flume was drained until the water level was flush with the sediment surface (Fig. 6C). Subsequently, porewater ammonium samples were taken in the test sections, and processed as previously described. The sediment where competent new juveniles were added was 


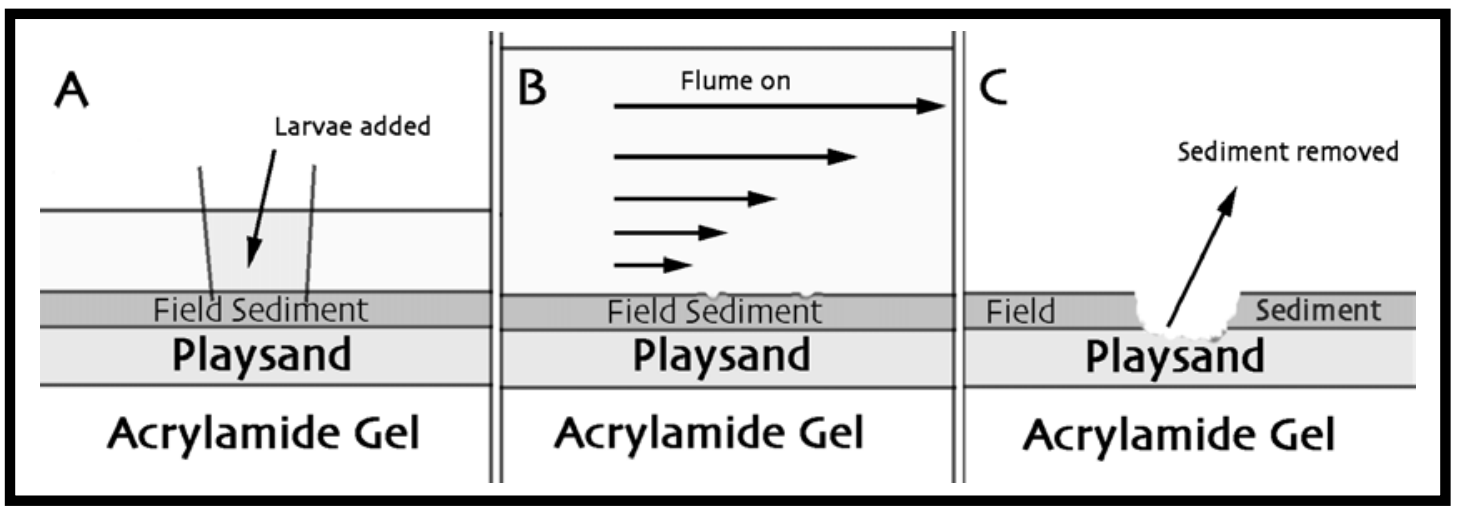

Figure 6. Diagram of new juvenile addition, flow initiation, and sampling sequence. Acrylamide gel was poured into flume sections. Store-bought sand (play sand) and then field sediment was added on top. The flume was filled halfway, and then the new juveniles were added to the sediment surface by pouring them into a plastic cylinder that encompassed a region of the sediment surface and allowing them to settle onto the surface for up to $35 \mathrm{~min}$ (A). The flume was then filled to a depth of 15 $\mathrm{cm}$ and flow turned on to 4.5 RPM for $8 \mathrm{~min}(\mathrm{~B})$, with a mean freestream velocity of $7.8 \pm 0.28 \mathrm{~cm} \mathrm{~s}^{-1}$. The flume was then drained and porewater samples taken just below the sediment surface using a needle and syringe and then filtered $(0.02 \mu \mathrm{m})$. The sediment where new juveniles were added was extracted, preserved, stained and later sorted for remaining individuals $(\mathrm{C})$. 
sampled to a depth of $2 \mathrm{~cm}$, preserved in buffered formalin, and stained with Rose Bengal. The entire experimental procedure, with freshly prepared acrylamide gels, was performed two additional times for a total of 3 trials.

Water column and porewater samples were refrigerated immediately and analyzed for ammonium concentration within $24 \mathrm{~h}$ of collection. The sediment samples were transferred to ethanol and then sorted under a dissecting scope to count number of individuals in the sample. This experiment was treated as a randomized complete block design with replication. Because the count data were treated as proportional, the data were transformed using an arcsin function. Analysis of the residuals from analyses of the homogeneity of variance for this experiment revealed that these data were normally-distributed and thus analyzed with ANOVA (SAS v.8.0, SAS Institute, Cary, NC 1999).

\section{B. Arenicola Experiments}

Egg masses of Arenicola cristata were obtained from Tom's Cove, Assateague, VA $\left(73^{\circ} 23^{\prime} \mathrm{W}, 37^{\circ} 56^{\prime} \mathrm{N}\right)$, at low tide on the $27^{\text {th }}$ of May, 2003. They were transported to the Chesapeake Biological Laboratory and reared as described above, to the 6-setiger stage where transition to a benthic existence occurs. Less than $6 \mathrm{~h}$ before the start of each trial, 75 new juveniles, were placed into each of 9 dishes. Representative individuals were chosen from the juvenile population and tested for competency and burrowing behavior as previously described. Sediment-acceptability tests indicated that rinsed ( 2 to 3 times) field sediment (Tom's Cove, VA, see above) was moderately acceptable. Of the 8 arenicolids tested, 5 burrowed in under 2 min; the other three did not burrow in the observation period $(>2 \mathrm{~min})$. The sediment used 
in the acceptability tests was rinsed at least 4 times and allowed to equilibrate for about $6 \mathrm{~h}$ as was done in the previous experimental trials in the flume. Three experimental trials were performed over $3 \mathrm{~d}$.

Nine test sections and nine unused sections were established with no two test sections directly adjacent in the flume. The treatments consisted of (1) Control (field sediment with no underlying gel), (2) Low (0 $\mu \mathrm{M}$ acrylamide (12\%) gel with play sand and field sediment on top, which conforms with the procedures used in the Mercenaria experiments described previously and (3) High (6,000 $\mu \mathrm{M}$ gel with play sand and field sediment on top). Within each flume run, treatments were replicated in triplicate and were randomly assigned to test sections. In this experiment I used field sediment with no gel as a control because previous efforts to limit ammonium flux from acrylamide gels (e.g., covering with plastic or use of KPS) were unsuccessful. Due to this failure, a behavioral response to the presence of the acrylamide, in the absence of ammonium could not be evaluated experimentally. However, a control without acrylamide provides insight into the recruitment response associated with natural field sediments.

Sediment trays were prepared as described previously. The procedure for preparing the flume, and adding individuals, followed the methods described above for the Mercenaria experiment, except for the number of treatments per trial (2 for Mercenaria, 3 for Arenicola) and the number of individuals (50 Mercenaria, 75 Arenicola) per replicate. Water column and porewater samples were refrigerated immediately and analyzed for ammonium concentration within $24 \mathrm{~h}$ of collection. The sediment samples were transferred to ethanol and then sorted under a dissecting 
scope to count number of individuals in the sample. As before, with proportional count data, it was necessary to perform an arcsin transformation. This experiment was treated as a randomized complete block design with replication. Analysis of the residuals from analyses of the homogeneity of variance for this experiment revealed that these data were normally distributed. Data were thus analyzed using ANOVA, conducted with SAS v.8.0 (SAS Institute, Cary, NC 1999). 


\section{Results}

\section{Preliminary Trials}

\section{A. Diffusion Experiments}

Ammonium was released from all treatments in the bare gel experiments due to the presence of ammonium persulfate as a cross linking agent (all treatments) and the addition of ammonium sulfate as a spike (500 and 2,000 $\mu \mathrm{M}$ treatments). Higher fluxes were associated with the magnitude of the ammonium spike (Fig. 7). In all cases, diffusion of ammonium from the gel ( surface area $=28.3 \mathrm{~cm}^{2}$ ) to the overlying water was linear $\left(\mathrm{F}=199.02, \mathrm{R}^{2}=0.9549 ; \mathrm{Fig} .1\right)$, and variability among replicates was quite low. Fluxes were significantly different between the $0 \mu \mathrm{M}$ concentration gel treatment and the 500 and 2,000 $\mu \mathrm{M}$ gel treatments (Fig. 7; analysis of variance: $\left.\mathrm{F}_{2,6}=7.46 p=0.0236\right)$.

Diffusion of ammonium was greatly reduced when the gels were covered with a layer of sediment (Fig. 8; ANOVA: $F_{3,11}=918.76, p<0.0001$ ). Results support the prediction that as sediment depth increased, the diffusional distance also increases, and over short incubation times, fluxes are reduced. Comparative tests (data not shown) suggest that ammonium adsorption onto play sand is greater than in fieldcollected sediment. Therefore, some ammonium adsorption onto play sand particles may have further reduced ammonium flux to the overlying water. Although the

plastic layer between sediment and gel reduced fluxes of ammonium slightly, I hoped to eliminate ammonium flux to create a true control. However, the plastic cover 


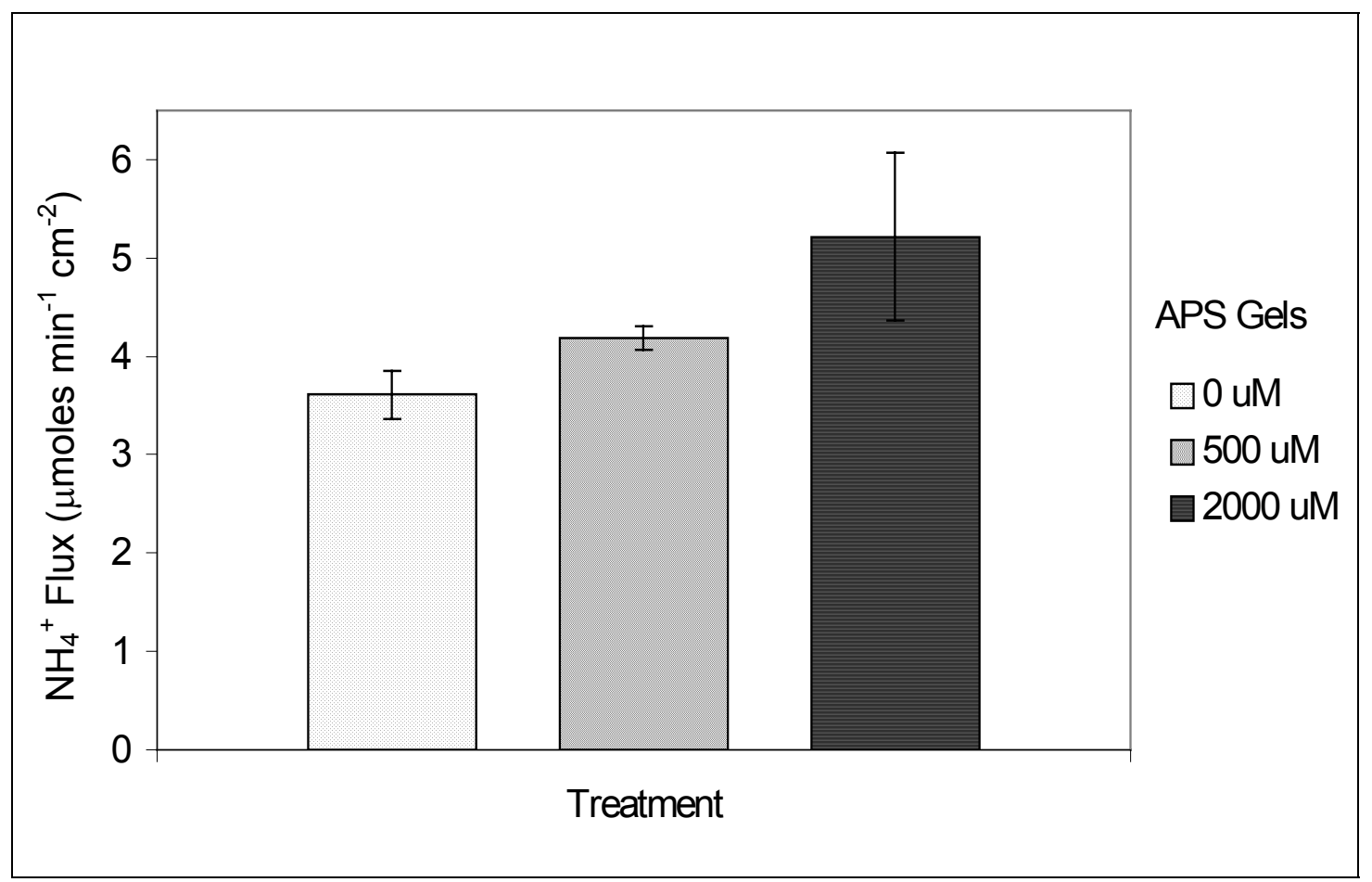

Figure 7. Flux of $\mathrm{NH}_{4}{ }^{+}$from bare (no sediment) acrylamide gels into overlying water. Gels were produced with 0,500 , and 2,000 $\mu \mathrm{M}$ ammonium sulfate solutions. Flux was calculated from change in overlying water concentration over $300 \mathrm{~min}$, and water column volume normalized to gel surface area. Bars are mean values \pm one standard deviation $(n=4)$. 


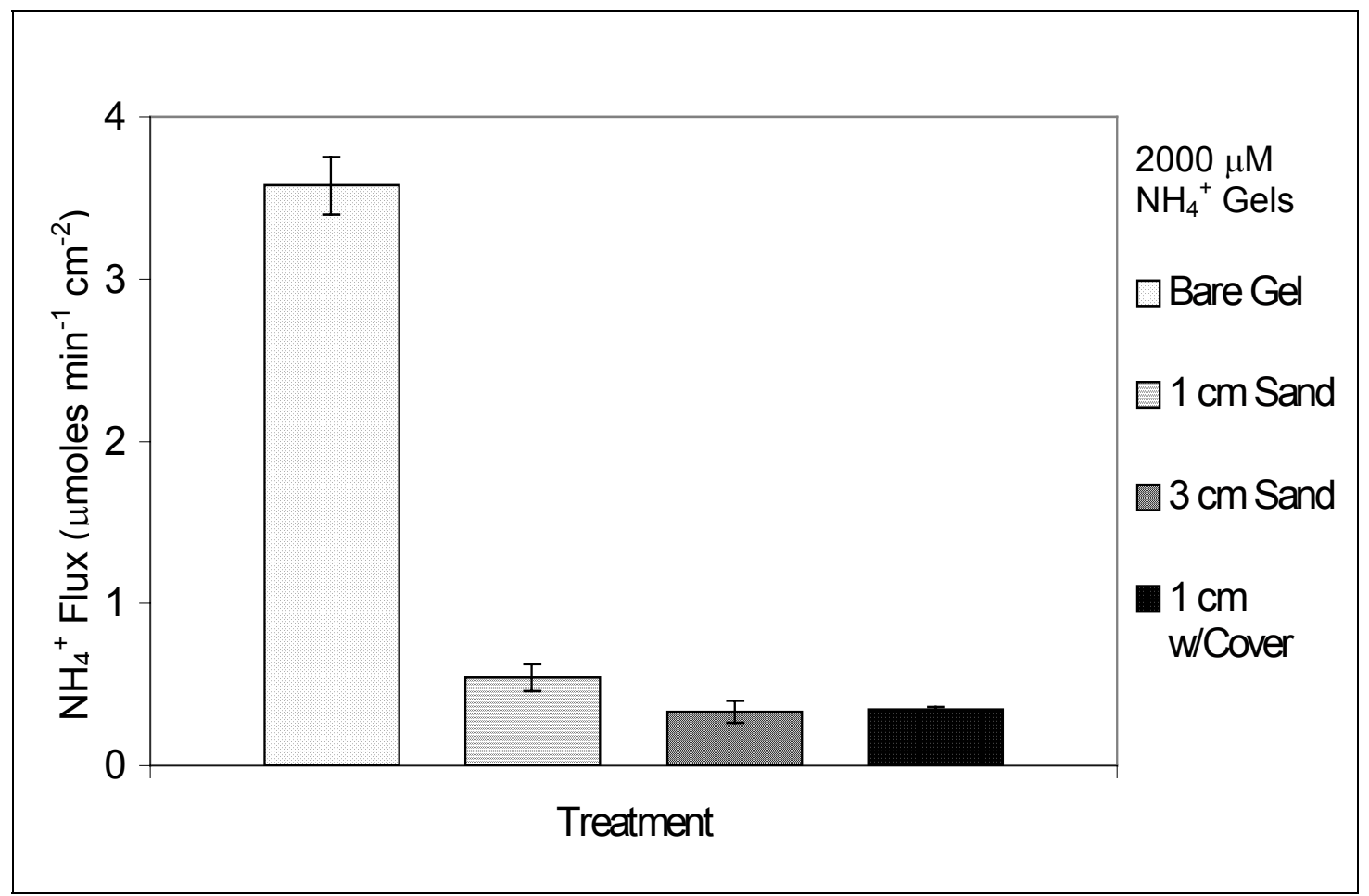

Figure 8. Flux of $\mathrm{NH}_{4}{ }^{+}$from acrylamide gels covered with varying depths of sediment on top of gels $(\mathrm{N}=3)$. Gels were produced with $2,000 \mu \mathrm{M}$ ammonium sulfate solutions with APS crosslinker and covered with 1 and $3 \mathrm{~cm}$ of play sand. Acrylamide gels used in the third treatment were covered with plastic cellophane and then $1 \mathrm{~cm}$ of play sand. Bars are mean values \pm one standard deviation $(\mathrm{n}=3)$. 
appeared to be permeable to ammonium and the flux could not be eliminated.

\section{B. Sandwich Flume Experiments}

Ammonium concentrations in water samples taken above the test sediments both prior and subsequent to addition of new juveniles of both Arenicola and Mercenaria were relatively low (mean $<3.0 \mu \mathrm{M}$ for "Medium" and $<8.4 \mu \mathrm{M}$ for "High") and within the range of water column concentrations for the North Inlet (Marinelli and Woodin, 2004). This suggests the disturbance of porewater associated with the addition of new juveniles was minimal. Samples of the incoming water used within the flume indicated ammonium concentrations were near zero (mean $<$ $0.001 \mu \mathrm{M})$. However, sediment porewater concentrations in low, medium, and high concentrations were elevated relative to the overlying water and were significantly different from one another (Fig. 9; $\mathrm{F}_{2,20}=42.01, p<0.0001$ ). These results suggest that the ammonium manipulation via acrylamide gels in flowing water was successful. Concentrations of porewater ammonium for the mid and high treatments were more than an order of magnitude higher than the low treatments, but still within the range of naturally occurring ammonium concentrations.

Results from the Jonckheere-Terpstra nonparametric ordered alternatives test indicate a significant difference $(\mathrm{p}=0.0046)$ in retention of Mercenaria among treatments but no difference for retention of Arenicola (Fig. 10). For Mercenaria, mean retention of new juveniles followed the predicted response for avoidance, i.e., higher retention for low ammonium sediments, and low retention in high ammonium sediments. The response from Arenicola was not consistent with avoidance of high 


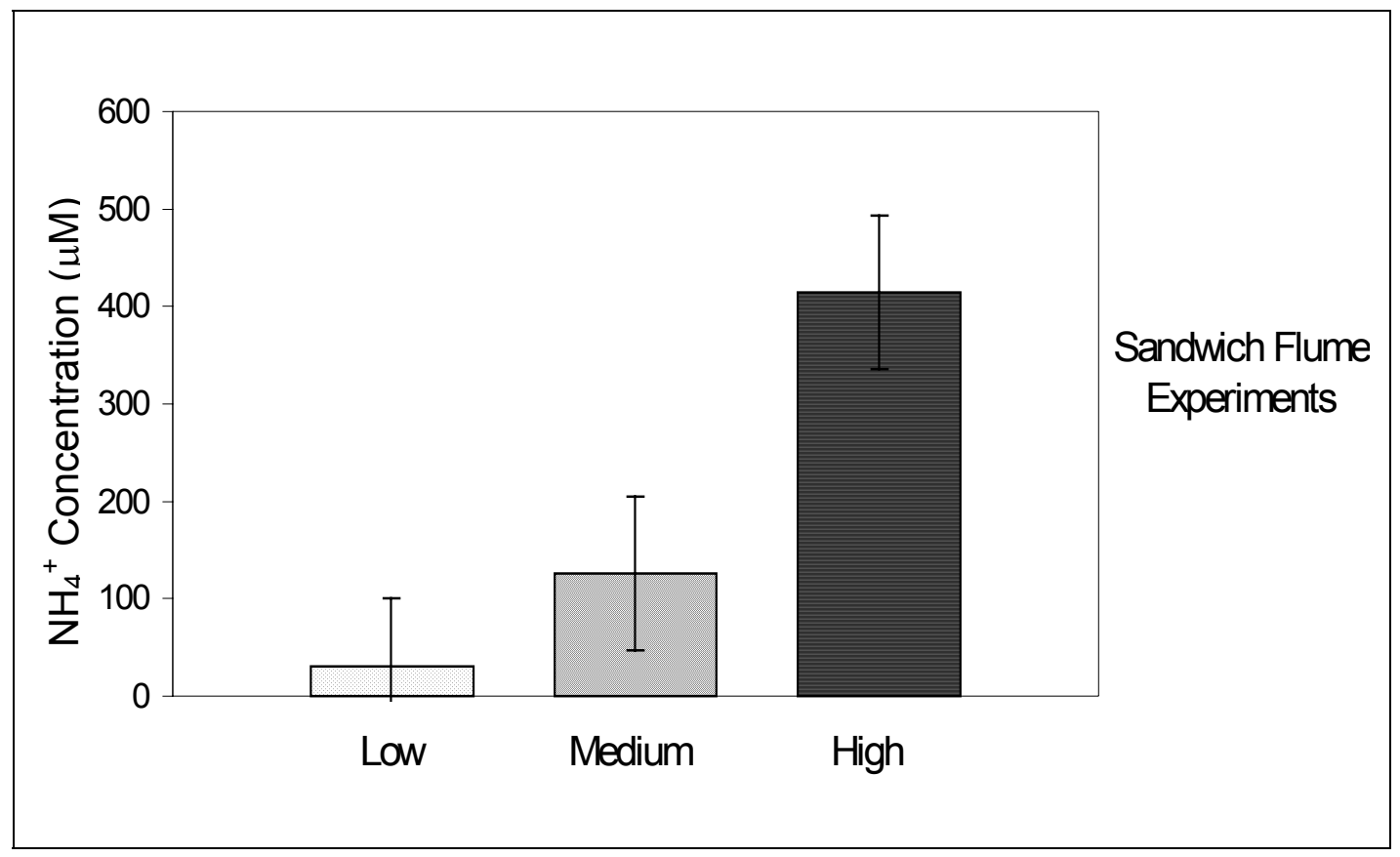

Figure 9. Porewater $\mathrm{NH}_{4}{ }^{+}$concentrations taken from top $0.5 \mathrm{~cm}$ of sediment surface for predesignated Low, Medium, and High treatments in the sandwich flume experiments. Bars are mean values \pm one standard deviation $(\mathrm{n}=8)$. 


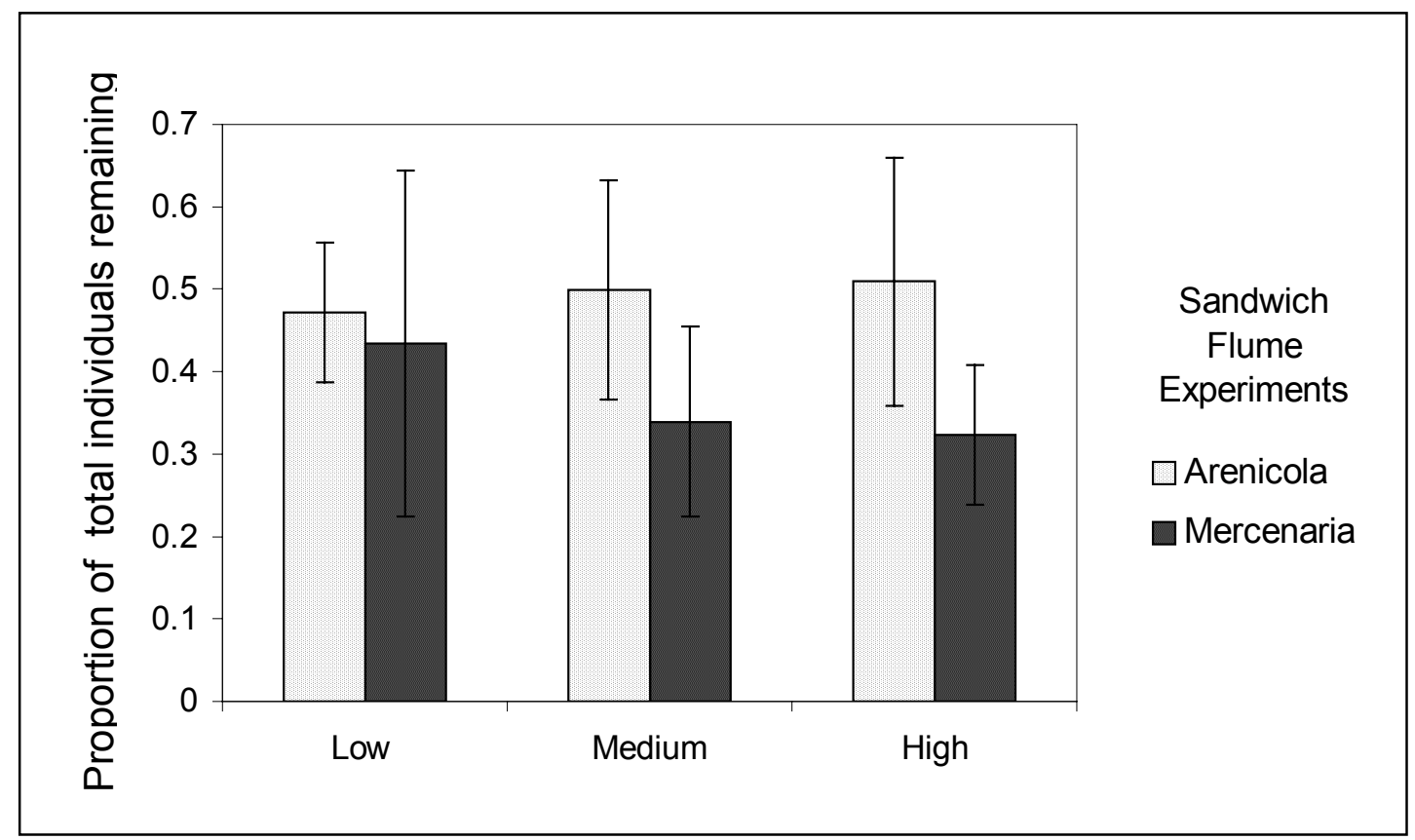

Figure 10. Proportion of juvenile Arenicola and Mercenaria individuals remaining in Low, Medium, and High $\mathrm{NH}_{4}{ }^{+}$concentration treatments compared to the total number added prior to flow for Sandwich Flume Experiments. Bars are mean values \pm one standard deviation. 
ammonium sediments, as in previous experiments (Woodin et al. 1998). Because retention rates for arenicolids were relatively low among all treatments, there was some possibility that play sand was not acceptable to the arenicolid new juveniles.

\section{Preliminary Annular Flume Trials}

Flow profiles yielded information concerning flow velocity, turbulence intensity, and shear velocity. Freestream velocities $(\mathrm{z} \geq 12 \mathrm{~mm}$ from sediment surface) averaged $7.79 \pm 0.21 \mathrm{~cm} \mathrm{~s}^{-1}$. Below $12 \mathrm{~mm}$, flow decreased to near zero just above the bed, following a typical log-linear relationship between distance from bed and velocity (Fig. 5). Although annular flumes often have secondary circulation and do not strictly obey a log-linear relationship, a detailed characterization of this flume (Porter 1999) indicated secondary circulation of $<7.2 \%$ at the flow speeds used in this experiment.

\section{Estimation of Shear Velocity}

Shear velocity $\left(\mathrm{u}_{*}\right)$ was calculated from the relationship between shear stress $\left(\tau_{\mathrm{b}}\right)$ and the water density $(\rho)$, (assumed to be 1.028 at $\sigma=28$; Equation 3 ).

$$
u_{*}=\sqrt{ }\left(\tau_{\mathrm{b}} / \rho\right)
$$

Shear stress $\left(\tau_{\mathrm{b}}\right)$ was calculated from the relationship between the drag coefficient

$\left(C_{D}\right)$, water density $(\rho)$, and mean freestream velocity $\left(U ; 7.79 \mathrm{~cm} \mathrm{~s}^{-1}\right.$; Equation 4$)$ as described in Porter 1999: 


$$
\tau_{\mathrm{b}}=\rho \mathrm{C}_{\mathrm{D}} \mathrm{U}^{2}
$$

The drag coefficient was estimated using the friction factor $(f)$ and the relationship $\mathrm{C}_{\mathrm{D}}=f / 8$. The friction factor is obtained from a Moody Diagram (Daily and Harleman 1966), which relates $(f)$ as a function of the Reynolds Number (Re; Equation 5) and the Relative roughness $\left(\mathrm{R}_{\mathrm{r}}\right.$; Equation 6) of a surface. The Reynolds number $(\mathrm{Re})$ is defined as:

$$
\mathrm{Re}=4 h \mathrm{U} / \mathrm{v}
$$

where $(\mathrm{v})$ is the kinematic viscosity of water $\left(1.0 \times 10^{-6} \mathrm{~m}^{2} \mathrm{~s}^{-1}\right)$. Relative roughness (Rr) is defined as:

$$
\mathrm{R}_{\mathrm{r}}=\mathrm{k}_{\mathrm{s}} / 4 h
$$

where $\left(\mathrm{k}_{\mathrm{s}}\right)$ is roughness element height and $\mathrm{h}$ is water column height $(h)$. Mean grain size of the field sediment $(0.03 \mathrm{~cm})$ was assumed to be a maximum roughness element height $\left(\mathrm{k}_{\mathrm{s}}\right)$ and the water column height $(h)$ was the same throughout all tests at $15 \mathrm{~cm}$. Relative roughness $\left(\mathrm{R}_{\mathrm{r}}\right)$ was thus found to be 0.005 and the calculated Reynolds number (Re) was $4.41 \times 10^{7}$. From the estimate of the friction factor $(f)$ at 0.0205 , obtained from the Moody Diagram, I calculated that $C_{D}$ was approximately $0.00256, \tau_{\mathrm{b}}$ was 0.1551 , thus $u_{*}$ was $0.394\left(\mathrm{~cm} \mathrm{~s}^{-1}\right)$. Shear velocities in this range 
indicate that drag on particles was not sufficient to cause significant erosion on the sediment surface, and that organisms remaining on the surface among sediment grains would not encounter drag forces that would remove them from the exploratory site. The possibility exists, however, that organisms modify their position to enhance drag and promote advection from the site. This has been observed for species such as Arenicola, where an individual will elevate its anterior, and then be removed from the site in a moderate flow (Woodin et al. 1998).

\section{Annular Flume Trials}

\section{A. Mercenaria Experiments}

Manipulation of porewater ammonium concentrations was successful. Differences between pre-addition and post-addition overlying and porewater samples from each treatment were much smaller than treatment differences (Fig. 11). There were significant differences in porewater ammonium concentration among treatments (analysis of variance: $\mathrm{F}_{1,14}=11.42 p=0.0045$; Fig. 12 , mean Low concentration $=$ $472 \mu \mathrm{M}$, mean High concentration= $921 \mu \mathrm{M})$. These concentrations were considerably higher than previous trials, perhaps because of desorption of ammonium during the extensive sediment rinsing process. Analysis of the sediment samples indicated that retention rates for all treatments were surprisingly low (overall mean $=0.0755 \pm 0.0758$ proportion of individuals found upon sediment sorting compared to initially added) and no treatment effect was found. It is possible that the high porewater ammonium concentrations (for example: trial 3 mean Low concentration $=714 \mu \mathrm{M}$, High concentration $=1,760 \mu \mathrm{M})$ found in all treatments 


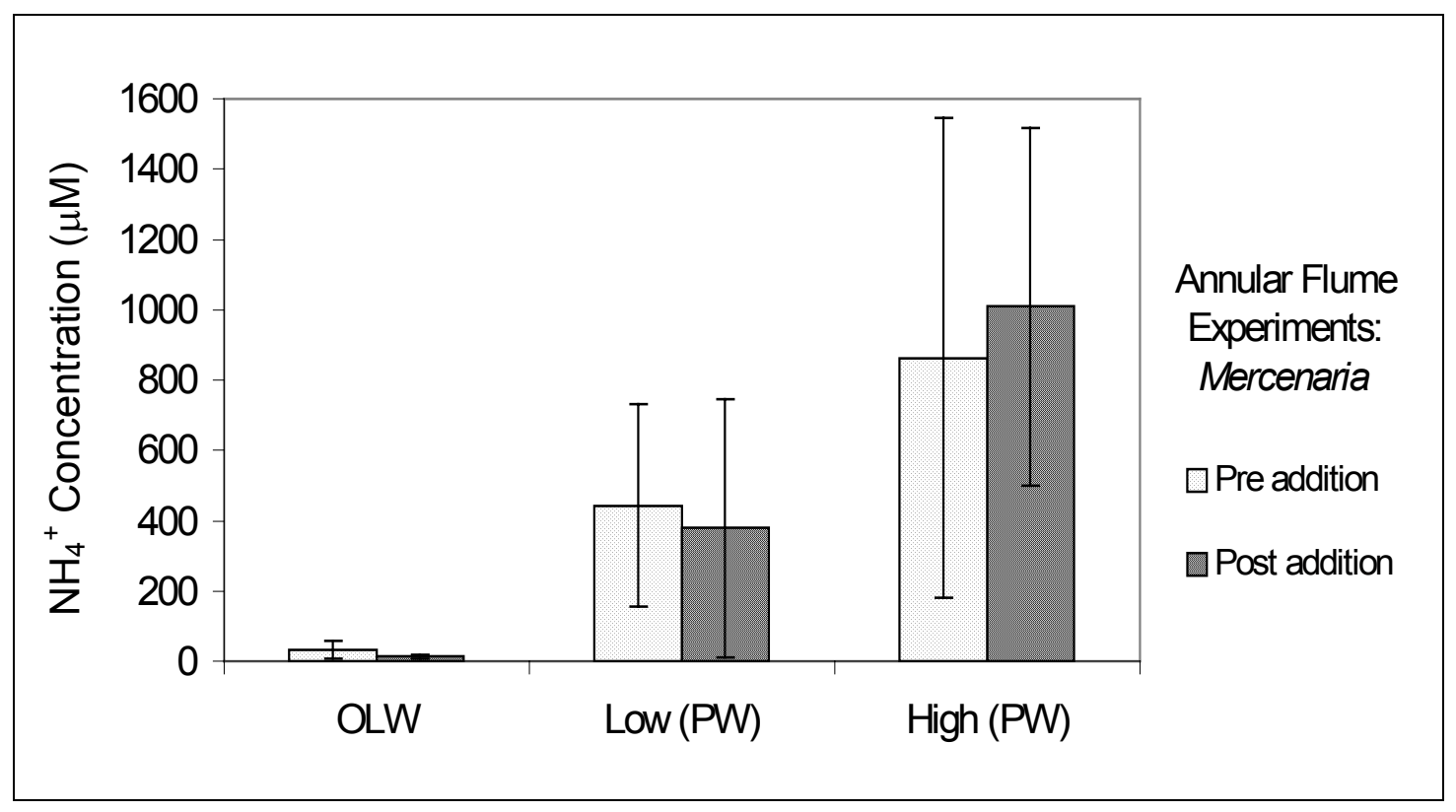

Figure 11. Test of the effect of new juvenile addition to overlying water (OLW) and porewater (PW, low and high) $\mathrm{NH}_{4}{ }^{+}$concentrations for each treatment in Mercenaria annular flume experiments. Pre- and post-addition samples were not significantly different from each other for each treatment. Bars are mean values \pm one standard deviation $(n=3)$. 


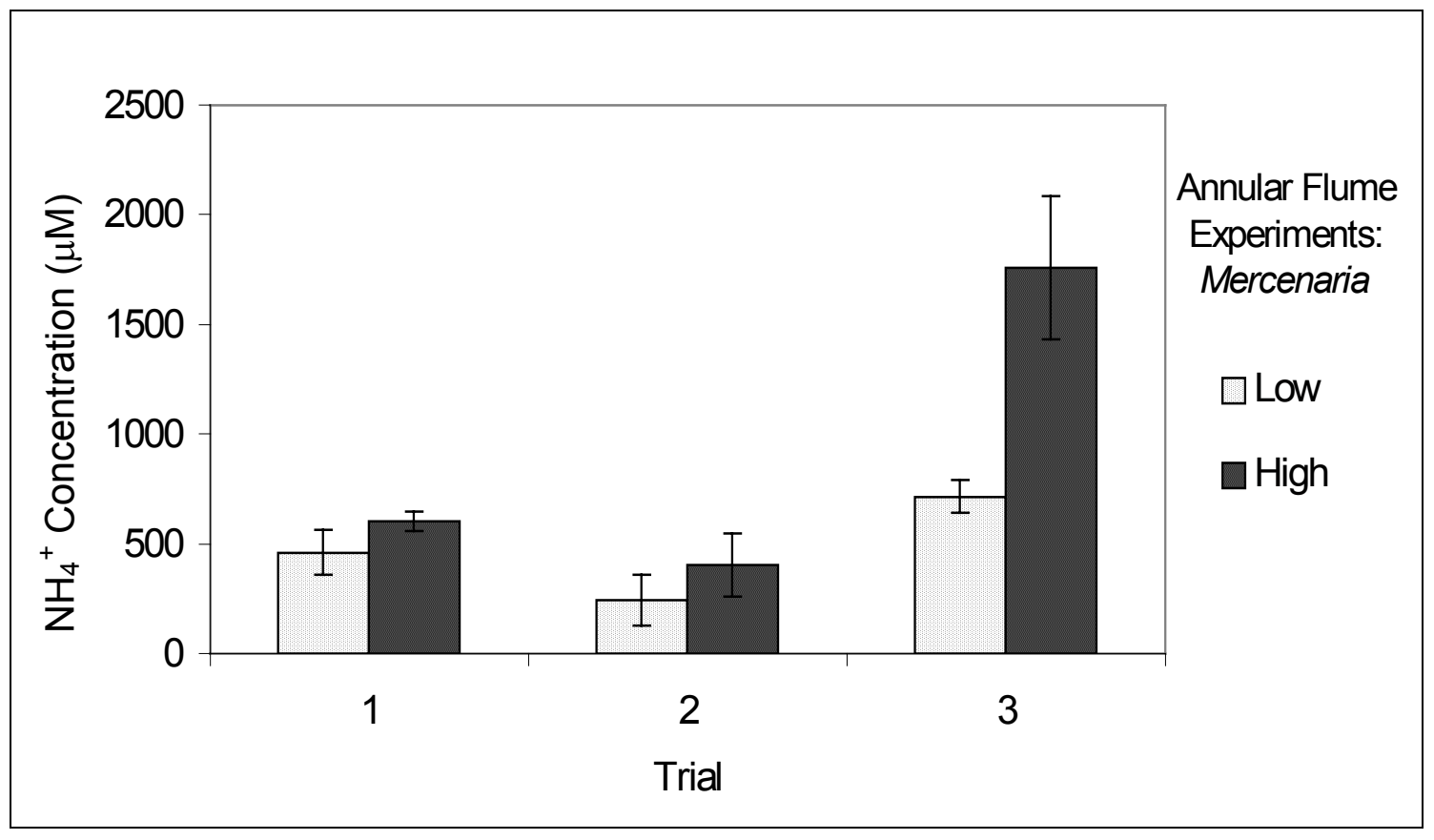

Figure 12. Porewater $\mathrm{NH}_{4}{ }^{+}$concentrations for Low and High ammonium concentration treatments for each Mercenaria trial in the annular flume experiments. Bars are mean values \pm one standard deviation $(n=3)$. 
caused rejection of the habitat, even in the low ammonium treatments.

\section{B. Arenicola Experiment}

Ammonium concentrations in water samples taken in the overlying water in the flume both prior and subsequent to addition of new juveniles were not significantly different $(\mathrm{p}=0.292)$. Similarly, differences between pre-addition and post-addition porewater samples from each treatment were much smaller than treatment differences (Fig. 13). Therefore, the treatment effects were much greater than the effects of addition and potential artifacts. Sediment porewater concentrations indicate that the ammonium manipulation was successful, with highest concentrations in the "High" treatment, which were significantly greater than the "Low" treatment, which was also greater than the "Control" (analysis of variance $\mathrm{F}_{2,24}=28.89$ $p<0.0001$; Fig. 14). Multiple comparisons of the least square treatment means of the porewater concentration data revealed that the Control, Low, and High treatments were significantly different from each other $\left(\mathrm{H}>\mathrm{L}>\mathrm{C}, \mathrm{F}_{2,24}=23.30, p<0.0001\right)$. Ammonium concentrations in the Control treatment averaged $87.02 \pm 35.37 \mu \mathrm{M}$ ammonium, suggesting that the rinsed, but further unmanipulated field sediments contained notable amounts of ammonium, possibly originating from breakdown of organic matter in sediments during the lengthy storage period.

Arenicolid juveniles also responded to the imposed treatments, showing higher retention in the "Control" and "Low" treatments relative to the "High" treatments (Fig. 15). Multiple comparisons tests of retention data indicated that the control and low treatments were not significantly different from each other, but both 


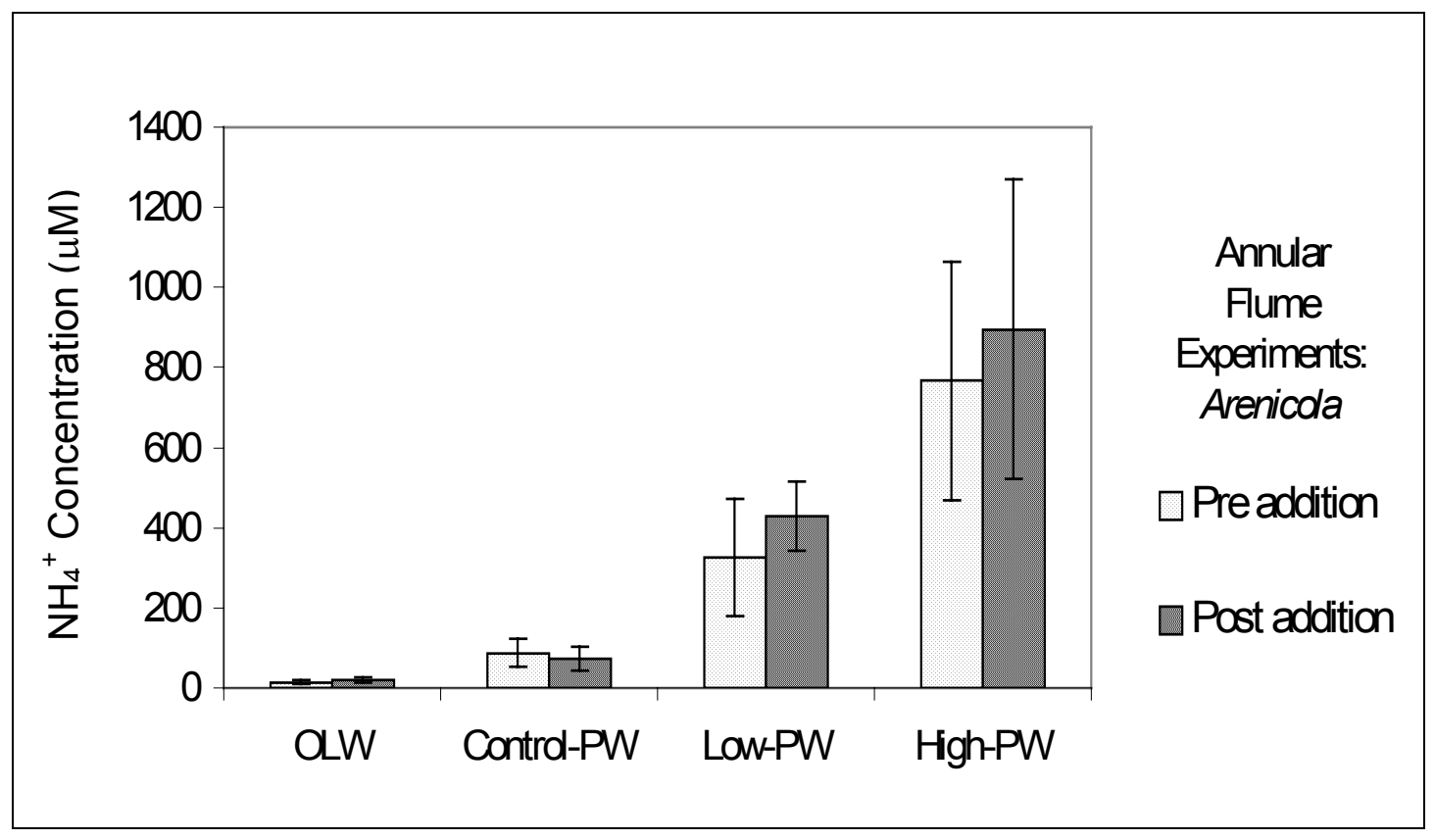

Figure 13. Test of the effect of new juvenile addition to overlying water (OLW) and porewater (PW, Low and High) $\mathrm{NH}_{4}{ }^{+}$concentrations for each treatment in Arenicola annular flume experiments. Pre and post-addition samples were not significantly different from each other for each treatment. Bars are mean values \pm one standard deviation $(n=3)$. 


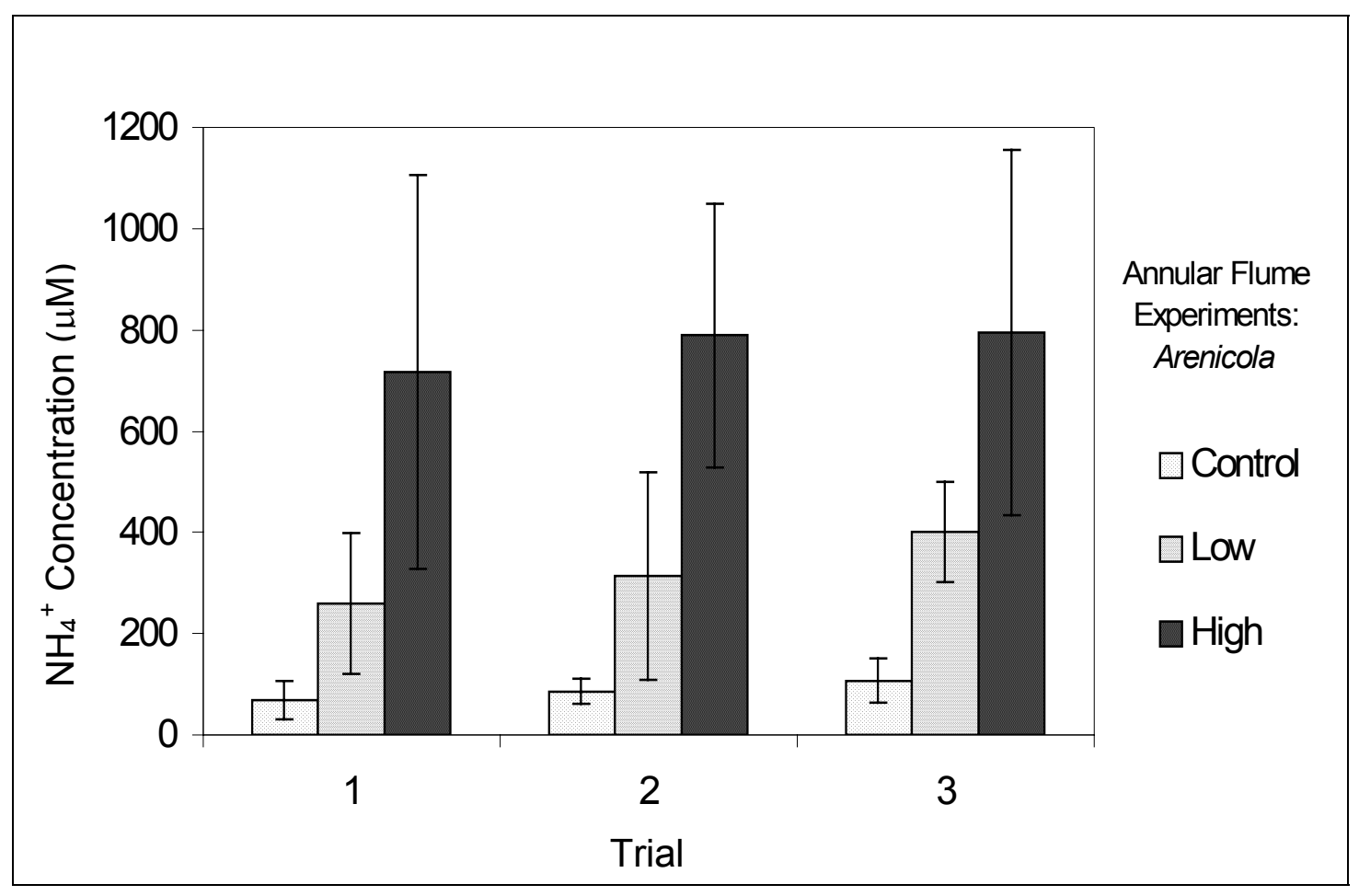

Figure 14. Porewater $\mathrm{NH}_{4}{ }^{+}$concentrations for Control, Low, and High $\mathrm{NH}_{4}{ }^{+}$ concentration treatments for each Arenicola trial. The control treatment had no acrylamide gel beneath the sediment surface. Bars are mean values \pm one standard deviation $(n=3)$. 


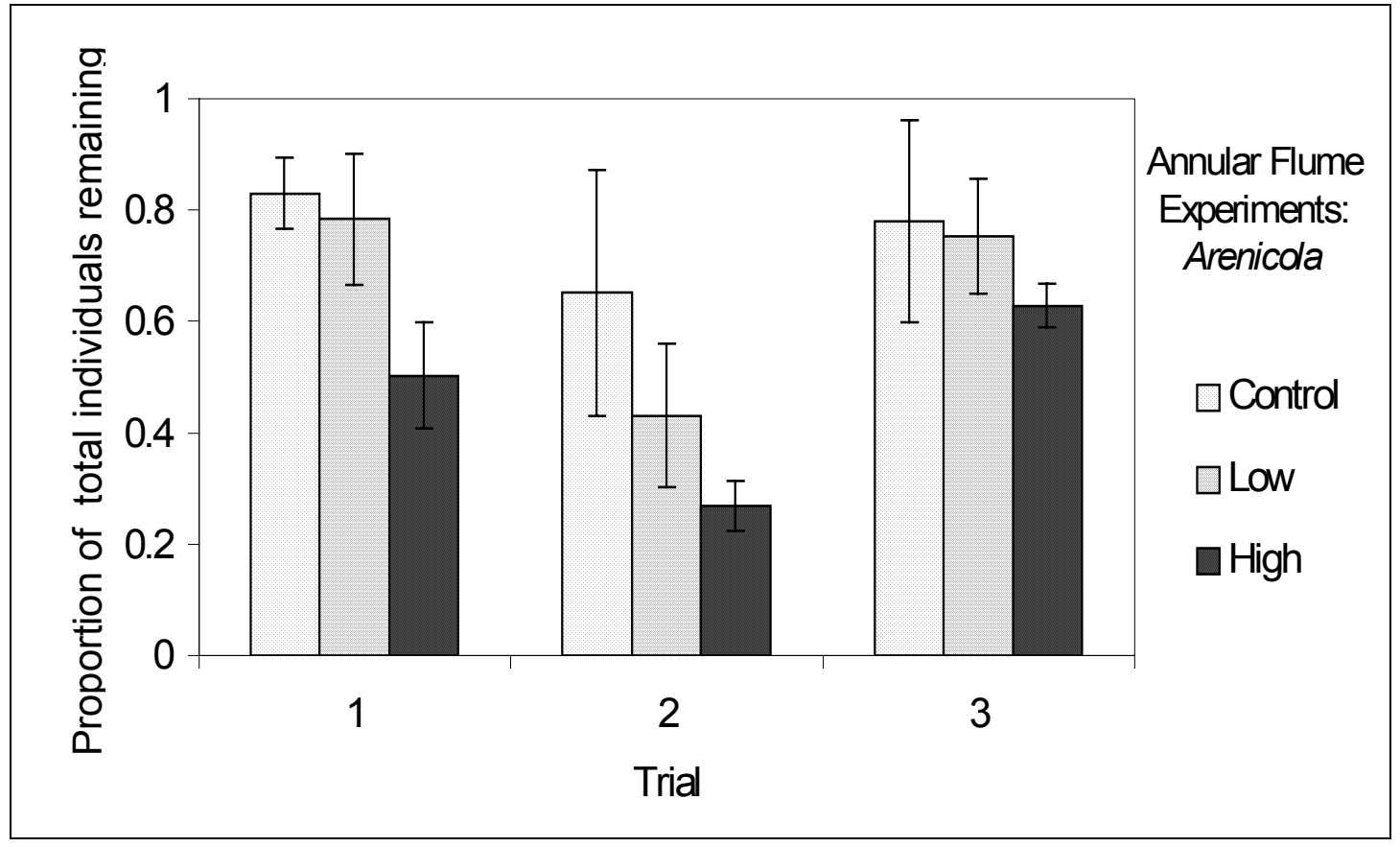

Figure 15. Proportion (arcsin transformed) of Arenicola cristata found in Control, Low, and High $\mathrm{NH}_{4}{ }^{+}$concentration treatments for all trials at end of experiment compared to number initially added. Bars are mean values \pm one standard deviation $(n=3)$. 
were significantly different from the high treatments $\left(\mathrm{H}<\mathrm{L}=\mathrm{C}, \mathrm{F}_{2,22}=12.23\right.$, $p=$ 0.0003). Thus, new juveniles appeared to leave the substrates with the highest ammonium levels. As sediment type, grain size, and flow were held constant it appears that retention was driven by surficial ammonium concentration. 


\section{Discussion}

Recruitment is an important process structuring community development and interactions in the benthos. In an environment where disturbances by browsing predators and surface deposit feeders abound, it may be costly for a new juvenile to select disturbed areas or to remain exposed on the sediment. Consequently, to enhance optimum site selection, it is advantageous for an organism to distinguish useful environmental signals from background information and to make recruitment decisions rapidly. Investigations of settling infauna have shown that organisms alter their recruitment choices as a function of disturbance, and that alteration of porewater chemistry covaries with disturbance intensity (Woodin et al. 1998). The current study furthers previous work through the development of a technique for manipulation of porewater chemistry while holding other variables constant, and for testing the recruitment response in the presence of flow.

\section{Porewater Manipulations}

My studies demonstrate that acrylamide gel diffusers offer a steady, predictable, and reproducible means of manipulating one solute while holding all other factors constant. Ammonium embedded within acrylamide gel successfully produced elevated porewater ammonium concentrations (Fig 7), which could be sustained during experimentation. Over short incubation times, increasing the diffusional distance by adding a sediment layer decreased flux rates and consequent porewater concentrations (Fig. 8), providing yet another technique for controlling 
concentration. Spiking of gels with ammonium sulfate led to higher porewater concentrations and higher fluxes than unspiked gels, although spiked sediments remained within the concentration ranges found in normal coastal sediments (e.g., Table 1 in Woodin et al. 1998). The diffusional and controlled-release characteristics are particularly useful for sediments because concentrations within the surrounding matrix are constantly shifting due to bioturbational activities. The ability to isolate substances allows further identification of important cues associated with diagenetic processes in sediments.

Porewater concentrations achieved through the manipulation were found to be different from each other within both sandwich flume and annular flume experiments. However in the annular flume trials, low, and control treatment concentrations were higher than expected (Figs. 12 and 14). Although concentrations were generally lower in the Arenicola annular flume experiment, both Arenicola and Mercenaria trials were affected by difficulties associated with the overlying sediment column. The storage of field sediment in $40 \mathrm{~cm}$ tall buckets may have resulted in ammonium buildup. Further, mixing of the sediment prior to use in the flume may have enhanced ammonium desorption (e.g., Aller 1994).

\section{New Juvenile Retention Data}

\section{A. Mercenaria Experiments}

In the sandwich flume experiments, Mercenaria showed a negative response to elevated porewater concentrations of ammonium, but the concentrations were 
much lower overall than in the annular flume experiments (Fig. 9). In the annular flume experiments, Mercenaria retention was lower than anticipated across all treatments. I believe that, under the given experimental porewater concentrations, no suitable settlement environment was offered to the settling Mercenaria juveniles, and thus very few remained in the sediment. The new juveniles chosen for each of the trials in this experiment had shed the velum (pediveligers), and likely departed the sediment surface via advection using local flow. All new juveniles used were deemed to be competent new juveniles, and thus differences in the recruitment response were likely a result of the treatment alone.

Other studies have found that exploratory time for Mercenaria on control sediment surfaces is longer on sediment surfaces that were disturbed, regardless of ammonium concentration (Marinelli and Woodin, 2004). It is possible that Mercenaria may be responding to another environmental parameter such as organic content (not measured in this study) or another covariate of disturbance that is not directly associated with ammonium. For example, in several settlement choice experiments Butman et al. (1988) showed that under realistic flow conditions similar to conditions observed in this study $\left(\mathrm{u} *=0.30 \mathrm{~cm} \mathrm{~s}^{-1}\right.$ Butman et al. $1988, \mathrm{u} *=0.39 \mathrm{~cm}$ $\mathrm{s}^{-1}$ current study), sediments with high organic content elicited higher recruitment of Capitella sp. I and Mercenaria than in sediment composed of abiotic glass beads of similar grain size. Bachelet et al. (1992) attempted to repeat the experiments performed by Butman et al. (1988) but had difficulty interpreting the Mercenaria response. They reported that no sediment selection was found for Mercenaria in their short-term (4 h), still water experiments, and that difficulties arose from determining 
a predictable peak competency period for this species. Retention of Mercenaria may have been equally low (or non-existent) in my trials possibly for similar reasons. Bachelet et al. (1992) further stated that given the difficulties with establishing competency of a large number of individuals, establishing a pertinent experimental time period was problematic. For the annular flume experiments I had to overcome similar obstacles, as sediment preparation required approximately $10 \mathrm{~h}$. As indicated earlier, these difficulties and the rapidity with which metamorphosis occurs, forced me to abandon a planned gel treatment of intermediate concentration.

\section{B. Arenicola Experiments}

Data from the sandwich flume experiment described above indicate no difference in response to sediments with elevated ammonium concentrations (Fig. 10) relative to control sediments. This response may be due to use of an unacceptable substrate in the sandwich flume experiment. The aged play sand was moderately acceptable to arenicolids in preliminary trials although burrowing times in natural sediment are usually more rapid (Marinelli and Woodin 2002). Retention of Arenicola in the annular flume experiments in sediments with elevated ammonium was consistently lower than in control sediments, supporting the hypothesis that ammonium serves as a negative cue (Fig. 15). These sediments consisted of natural particles plus play sand and under low ammonium concentrations may have been more attractive. In the annular flume experiments, retention of Arenicola was higher than retention in trials with Mercenaria, while ammonium concentrations were generally lower, indicating that more favorable environmental conditions were produced in all Arenicola trials. The fact that differences in retention of arenicolids 
were found when all other factors were held the same (flow environment, sediment type, etc.) illustrates that the new juveniles were responding to elevated porewater ammonium concentrations.

\section{Methodological Considerations}

The effort required for the development of the methods used to test the recruitment response was considerable. The successful and reliable production of acrylamide gel spiked with known concentrations of ammonium involved some trial and error to arrive at the proper acrylamide concentration (12\%) for the trials. As noted above, the use of a persulfate binding agent other than APS would be desirable to produce a true ammonium control, but due to the significance of other ions (such as $\mathrm{K}^{+}$and $\mathrm{Na}^{+}$) to both complex and sensitive biological reactions, this could not be further explored. Non-APS gels may also have different physical characteristics as well (density, pore size, setting time), possibly affecting the diffusional characteristics of the gel. Such efforts require additional testing and development before use in experimental trials.

Further methodological problems arose when the experimental protocols were expanded. For example, variance in concentration data increased greatly as play sand, and then stored field sediment, was added to the experimental procedures. Presumably, much of the variance in concentration data originated from variability in sediment characteristics (sediment type, rinsing, sediment depth, storage conditions, etc.). However, it is also possible that variability in recruit response in preliminary 
acceptability tests as well as during experiment was from natural sediment variability unrelated to ammonium per se.

Hydrodynamic characterization of conditions within the annular flume was based on several assumptions, such as an estimation of shear velocity from shear stress and water density when a log-linear relationship between freestream velocity and shear velocity was not valid. In spite of these assumptions, velocity data taken with an ADV, after experimental procedures were completed, confirmed that the flume boundary layer resembled a log-linear form. Under ideal conditions, velocity data would be taken during each experiment, but this was not compatible with experimental procedures such as the exploratory time limit.

\section{Significance of Post-Settlement Choice}

Benthic infauna are most vulnerable to mortality as early juveniles. My findings suggest that, for species similar to Arenicola and Mercenaria, active choice and exploratory behavior is critical for successful recruitment in heterogeneous environments. In general, mortality decreases as an organism becomes older and as a result, factors affecting early mortality play key roles in determining patterns of population abundance. In a hard substrate environment, Gosselin and Qian (1996) underscored the vulnerability of the first days after settlement for the barnacle Balanus glandula. They reported greater than 50\% mortality for specific cohorts during the first $4 \mathrm{~d}$, with the majority of deaths during a period shorter than the first day. They also suggest that the selective pressures for traits such as time of settlement, the rapidity at which an individual settles, and the identification of the 
causes of mortality play significant roles in determining early juvenile traits and recruit success. The experiments described above emphasize that in soft sediment systems, habitat choice is rapid, and disturbance/mortality cues play a role in that choice. Recruit success in sedimentary systems may be similarly impacted by these early decisions.

In a study of settlement of the intertidal barnacle Tesseropora rosea, Caffey (1985) suggested that the spatial and temporal predictability of disturbance processes affecting new recruits, and subsequent mortality, is far less certain than for established adult populations. Few studies quantify the spatial and temporal fidelity of disturbance events in soft sediments, although some (e.g., Krager and Woodin, 1993) suggest a moderate degree of predictability. Clearly, the scale dependent nature of disturbance and recolonization (Gunther 1992) will have a strong impact on determining the relationship between recruitment success and adult population structure. Findings from the present study support the idea that spatial heterogeneity in geochemical conditions associated with disturbed surfaces can lead to differential patterns in settlement. The significance of spatial scales of geochemical disturbance to recruitment choice remains relatively unexplored.

\section{Conclusions}

Many studies have shown the existence of cues in natural environments and there is evidence that many benthic species can perceive and respond to substances that are associated with favorable or unfavorable environments (see review by Rodríguez et al. 1993; Pawlik 1992; Woodin 1991). This study confirms that 
ammonium, in isolation from other porewater solutes, is an important recruitment cue. Previous studies have linked ammonium concentrations with disturbance and suggest that by avoiding them new juveniles may enhance recruitment success. Many settlement cues, however, are positive, e.g., those from adult conspecifics or food resources of adults (e.g., Raimondi 1990; Pawlik 1992; Zimmer-Faust and Tamburri 1994; Browne and Zimmer 2001; Kay 2002) or microbial films connected to adult communities (Coon et al. 1985). Regardless of their positive or negative effects, the elucidation of how chemistry and associated covariates within sediments affect recruitment behavior is decidedly more complicated than in pelagic environments. Diagenetic processes, physical factors, and bioturbational events combine to produce a matrix of signals that often covary and result in significant small-scale spatial and temporal variation in chemical signals. Studies that can separate these signals will significantly advance our understanding of recruitment processes in soft sediment systems.

The behavioral response to ammonium yields only a small fraction of information about recruitment processes. My findings, however, clarify that ammonium may play an important role in determining settlement patterns that are associated with disturbance processes. Manipulation of the geochemical environment and controlling the hydrodynamic environment while holding all other factors constant sheds light on the recruitment response to a specific geochemical signal. The species I tested represent ecologically important species in benthic community dynamics, as they are common and broadly distributed in temperate soft sediment ecosystems. Findings from these experiments also indicate that gel diffusers can be 
used to manipulate a single geochemical solute and it is possible that other biologically significant solutes can be investigated with similar simplicity. While numerous studies have shown that biological communities affect the chemical environment, my findings add to the state of understanding of how chemistry and the chemical environment affect community ecology. Similarly, this work contributes valuable and pertinent information to body of knowledge concerning the recruitment response of relatively important species in a geochemically and hydrodynamically realistic environment. 


\section{REFERENCES}

Aller, R.C. 1994. Bioturbation and remineralization of sedimentary organic matter: Effects of redox oscillation. Chem. Geol. 114:331-345.

Aller, R.C. and J.Y. Aller. 1998. The effect of biogenic irrigation intensity and solute exchange on diagenetic reaction rates in marine sediments. J. Mar. Res. 56: 905-936.

Ambrose, W.G., Jr. 1986. Experimental analysis of density dependent emigration of the amphipod Rhepoxynius abronius, Mar. Behav. Physiol. 12:209-216.

Andre, C and R. Rosenberg. 1991. Adult-larval interactions in the suspension-feeding bivalves Cerastoderma edule and Mya arenaria. Mar. Ecol. Prog. Ser. 71(3):227-234.

Bachelelet, G., C. A. Butman, C. M. Webb, V. R. Starczak, and P. V. R. Snelgrove . 1992. Non-selective settlement of Mercenaria mercenaria (L.) larvae in short-term, still-water, laboratory experiments. J. Exp. Mar. Biol. Ecol. 161: 241-280.

Bianchi, T.S. and D.L. Rice. 1988. Feeding ecology of Leitoscolopolos fragilis. Mar. Biol. 99:123-131. 
Biggers, W.J. and H. Laufer. 1999. Settlement and metamorphosis of Capitella larvae induced by juvenile hormone-active compounds is mediated by protein kinase $\mathrm{C}$ and ion channels. Biol. Bull. 196:187-198.

Browne, K.A., and R.K. Zimmer. 2001. Controlled field release of a waterborne chemical signal stimulates planktonic larvae to settle. Biol. Bull. 200:87-91.

Burton, J.D. 1976. Estuarine Chemistry. J.D. Burton and P.S. Liss (eds.) Academic Press, London.

Butman, C.A. 1987. Larval settlement of soft-sediment invertebrates: the spatial scales of pattern explained by active habitat selecation and the emerging role of hydrodynamic processes. Oceanogr. Mar. Biol. Annu. Rev. 25:113-165.

Butman, C.A., J.P. Grassle and E.J. Buskey. 1988a. Horizontal swimming and gravitational sinking of Capitella sp. I (Annelida: Polychaeta) larvae: Implications for settlement. Ophelia 29:43-57.

Butman, C.A., J.P. Grassle and C.M. Webb. 1988b. Substrate choices made by marine larvae settling in still water and in a flume flow. Nature 333:771-773. 
Butman, C.A. 1989. Sediment-trap experiments on the importance of hydrodynamical processes in distributing settling invertebrate larvae in near-bottom waters. J. Exp. Mar. Biol. Ecol. 134(1):37-88.

Butman, C.A. and J.P. Grassle. 1992. Active habitat selection by Capitella sp. I larvae. 1. Two-choice experiments in still water and flume flows. J. Mar. Res. 50:669-715.

Caffey, H.M. 1995. Spatial and temporal variation in settlement and recruitment of intertidal barnacles. Ecol. Monogr. 55:313-332.

Connell, J. H. 1978. Diversity in tropical rain forests and coral reefs. Science 199: 1302-1310.

Coon, S.L., D.B. Bonar and R.M. Weiner. 1985. Induction of settlement and metamorphosis of the Pacific oyster, Crassostrea gigas (Thunberg), by L-DOPA and catecholamines. J. Exp. Mar. Biol. Ecol. 94:211-221.

Crisp, D.J. 1974. Factors influencing settlement of marine invertebrate larvae. p. 177265 In P.T. Grant \& A. M. Mackie [eds.],Chemoreception in Marine Organisms. New York, New York. 
Cuomo, M.C. 1985. Sulphide as a larval settlement cue for Capitella sp I.

Biogeochem. 1:169-181.

Daily, J.W. and D.R.F. Harleman 1966. Fluid Dynamics. Addison-Wesley Publishing Company, Inc.

Dayton, PK. 1971. Competition, disturbance, and community organization: the provision and subsequent utilization of space in a rocky intertidal community. Ecol. Monogr. 41:351-389.

Diaz, R., J. and R. Rosenberg. 1995. Marine benthic hypoxia: A review of its ecological effects and the bahavioural responses of benthic macrofauna. Oceanogr. and Mar. Biol., Ann. Rev. 33:245-303.

Dubilier, N. 1988. H2S - A settlement cue or a toxic substance for Capitella sp. I Larvae. Biol. Bull. 174:30-38.

Eckman, J.E. 1979. Small-scale patterns and processes in a soft substratum, intertidal community. J. Mar. Res. 39:437-457.

Eckman, J.E. 1983. Hydrodynamic processes affecting benthic recruitment. Limnol. Oceanogr. 28:241-257. 
Eckman, J.E. 1990. A model of passive settlement by planktonic larvae onto bottoms of differing roughness. Limnol. Oceanogr. 35:887-901.

Ekman, S. 1967. Zoogeography of the sea, 2nd edition. Sidgwick and Jackson.

Finelli, C.M., D.D. Hart and D.M. Fonseca. 1999. Evaluating the spatial resolution of an acoustic Doppler velocimeter and the consequences for measuring near-bed flows. Limnol. Oceanogr. 44:1793-1801.

Fitt, W.K. and S.L. Coon. 1992. Evidence for ammonia as a natural cue for recruitment of oyster larvae to oyster beds in a Georgia salt marsh. Biol. Bull. 182:401-408.

Gosselin, L.A. and P.Y Qian. 1996. Early post-settlement mortality of an intertidal barnacle: a critical period for survival. Mar. Ecol. Prog. Ser. 135:69-75.

Gross, T.F., F.E. Werner, and J.E. Eckman. 1992. Numerical modeling of larval settlement in turbulent bottom boundary layers. J. Mar. Res. 50:611-642.

Gunther, C. 1992. Dispersal of intertidal invertebrates: a strategy to reacto to disturbances of different scales? Neth. J. Sea Res. 30:45-56. 
Hardege, J.D., M.G. Bentley and L. Snape. 1998. Sediment selection by juvenile Arenicola marina. Mar. Ecol. Prog. Ser. 166:187-195.

Hollander, M. and D.A. Wolfe 1973. Nonparametric Statistical Methods. Wiley and Sons. New York

Huettel, M.W. Ziebis and S. Forster. 1996. Flow-induced uptake of particulate matter in permeable sediments. Limnol. Oceanogr. 41:309-322.

Kay, M.C. 2002. Recruitment in the intertidal limpet Lottia digitalis (Patellogastropoda: Lottiidae) may be driven by settlement cues associated with adult habitat. Mar. Biol. 141(3):467-477.

Krager, C. D. and S. A. Woodin.1993. Spatial persistence and sediment disturbance of an arenicolid polychaete. Limnol. Oceanogr. 38(3): 509-520.

Koroleff, F. 1976. Determination of ammonia. Pages 126-133 IN Grasshoff, K., (ed.) Methods of seawater analysis. Verlag Chemie, Weinheim.

Levin, L.A. 1984. Life history and dispersal patterns in a dense infaunal polychaete assemblage: community structure and response to disturbance. Ecology 65:11851200. 
Levin, L.A., 1986. Effects of enrichment on reproduction in the opportunistic polychaete Streblospio benedicti (Webster): A mesocosm study. Biol. Bull. 171:143160.

Marcus, N.H. and F. Boero. 1998. Minireview: The importance of benthic-pelagic coupling and the forgotten role of life cycles in coastal aquatic systems. Limnol. Oceanogr. 43:763-768.

Marinelli, R.L. 1994. Effects of burrow ventilation on activities of a terebellid polychaete and silicate removal from sediment pore waters. Limnol. Oceanogr. 39: 303-317.

Marinelli, R.L. and S.A. Woodin. 2002. Experimental evidence for linkages between infaunal recruitment, disturbance and sediment surface chemistry. Limnol. Oceanogr. 47:221-229.

Marinelli, R.L. and T.J. Williams. 2003. Evidence for density-dependent effects of infauna on sediment biogeochemistry and benthic-pelagic coupling in nearshore systems. Estuarine Coastal Shelf Sci. 57:179-192.

Marinelli, R.M. and S.A. Woodin. 2004. Disturbance and rectuirment: A test of solute and substrate specificity using Mercenaria mercenaria and Capitella sp. 1. Mar. Ecol. Prog. Ser. 269:209-221. 
McEdward, L., ed. 1995. Ecology of Marine Invertebrate Larvae. CRC Press, Boca Raton, Florida.

Navarette, S.A. and E.A. Weiters. 2000. Variation in barnacle recruitment over small scales: larval predation by adults and maintenance of community pattern. J. Exp. Mar. Biol. Ecol. 253:131-148.

National Marine Fisheries Service. 2003. Personal communication from the National Marine Fisheries Service, Fisheries Statistics and Economics Division, Silver Spring, MD.

Ólafsson, E.B., C.H. Peterson and W.G. Ambrose, Jr. 1994. Does recruitment limitation structure populations and communities of macroinvertebrates in marine soft sediments: The relative significance of pre-and post-settlement processes. Oceanogr. Mar. Biol. Ann. Rev. 32:65-109.

Osman, R.K. and R. B. Whitlatch. 1995. The influence of resident adults on recruitment: a comparison to settlement. J. Exp. Mar. Biol. Ecol. 190:169-198.

Pawlik, J.R. 1988. Larval settlement and metamorphosis of sabellariid polychaetes, with special reference to Phragmatopoma lapidosa, a reef-building species, and Sabellaria floridensis, a non-gregarious species. Bull. Mar. Sci. 43:41-60. 
Pawlik, J.R. 1990. A symposium on chemical factors that influence the settlement and metamorphosis of marine invertebrate larvae: Introduction and perspective. Bull. Mar. Sci. 46:450-454.

Pawlik, J.R. 1992. Chemical ecology of the settlement of benthic marine invertebrates. Oceanogr. Mar. Biol. Ann. Rev. 30:273-335.

Pearson, T. H. and R. Rosenberg. 1978. Macrobenthic success in a relation to organic enrichment and pollution of the marine environment. Oceanogr. Mar. Biol. Ann. Rev. $16: 229-311$.

Porter, E.T. 1999. Physical and biological scaling of benthic-pelagic coupling in experimental ecosystem studies. University of Maryland (College Park, MD). Marine, Estuarine, Environmental Sciences Graduate Program.

Powers, S.P. and C.H. Peterson. 2000. Conditional density dependence: The flow trigger to expression of density-dependent emigration in bay scallops. Limnol. Oceanogr. 45:727-732.

Raimondi, P.T. 1990. Patterns, mechanisms, consequences of variability in settlement and recruitment of an intertidal barnacle. Ecol. Monogr. 60:283-309. 
Rhoads, D.C. 1974. Organism-sediment relations on the muddy sea floor. Oceanogr. Mar. Biol. Ann. Rev. 12:263-300.

Rodríguez, S.R., F.P. Ojeda and N.C. Inestrosa. 1993. Settlement of benthic marine invertebrates. Mar. Ecol. Prog. Ser. 97(2):193-207.

Rodríguez, S.R, C. Riquelme, E.O. Campos, P. Chavez, E. Brandan and N.C. Inestrosa. 1995. Behavioral responses of Concholepas concholepas (Bruguiére, 1789) larvae to natural and artifical settlement cues and microbial films. Biol. Bull. 189:272-279.

Rusch, A. and M. Huettel. 2000. Advective particle transport into permeable sediments - evidence from experiments in an intertidal sandflat. Limnol. Oceanogr. 45:525-533.

SAS Institute Inc. Version 8, Cary, NC: SAS Institute Inc., 1999.

Scheltema, R.S. 1974. Biological interactions determining larval settlement of marine invertebrates. Thalassia Jugosl. 10:423-453.

Snelgrove, P.V.R. and C.A. Butman. 1994. Animal-sediment relationships revisited: Cause versus effect. Oceanogr. Mar. Biol. Ann. Rev. 32:111-177. 
Strathmann, R.R. 1993. Hypotheses on the Origins of Marine Larvae. Ann. Rev. Ecol.Syst. 24:89-117.

Strathmann, R. R., T. P. Hughes, A. M. Kuris, K. C. Lindeman, S. G. Morgan, J. M. Pandolfi, and R. R. Warner. 2002. Evolution of local recruitment and its consequences for marine populations. Bull. Mar. Sci. 70 Suppl:377-396.

Sutherland, J. P. 1974. Multiple stable points in natural communities. Am. Nat. 108:859-873.

Tamburri, M.N., C.M. Finelli, D.S. Wethey, and R.K. Zimmer-Faust. 1996. Chemical induction of larval settlement behavior in flow. Biol. Bull. 191:367-373.

Thorson, G. 1950. Reproductive and larval ecology of marine bottom invertebrates. Biol. Rev. 25:1-45.

Thorson, G. 1966. Some factors influencing the recruitment and establishment of marine benthic communities. Neth. J. Sea. Res. 3:267-293.

Tilman, D., J. Knops, D. Wedin, P. Reich, M. Ritchie, and E. Siemann. 1997a. The influence of functional diversity and composition on ecosystem processes. Science 277:1300-1302. 
Turner, E.J., Zimmer-Faust, R.K., Palmer, M.A., Luckenbach, M. and N.D.

Pentcheff. 1994. Settlement of oyster (Crassostrea virginica) larvae: Effects of water flow and a water-soluble chemical cue. Limnol. Oceanogr. 39:1579-1593.

Woodin, S.A. 1986. Settlement of infauna: larval choice? Bull. Mar. Sci. 39:401-407.

Woodin, S.A. 1991. Recruitment of infauna: positive or negative cues? Am. Zool. $31: 797-807$

Woodin, S.A. and R.L. Marinelli. 1991. Biogenic habitat modification in marine sediments: The importance of species composition and activity. In The Environmental Impact of Burrowing Animals and Animal Burrows. Symposium of the Zoological Society of London 63: 231-250

Woodin, S.A., R.L. Marinelli and D.E. Lincoln. 1993. Allelochemical inhibition of recruitment in sedimentary assemblages. J. Chem. Ecol. 19: 517-530.

Woodin, S.A., S.M. Lindsay and D.S. Wethey. 1995. Process-specific recruitment cues in marine sedimentary systems. Biol. Bull. 189:49-58.

Woodin, S.A., R.L. Marinelli and S.M. Lindsay. 1998. Process-specific cues for recruitment in sedimentary environments: Geochemical signals? J. Mar. Res. 56:535558. 
Zimmer-Faust, R.K., and M.N. Tamburri (1994) Chemical identity and ecological implications of a waterborne, larval settlement cue. Limnol. Oceanogr. 39: 10751087 